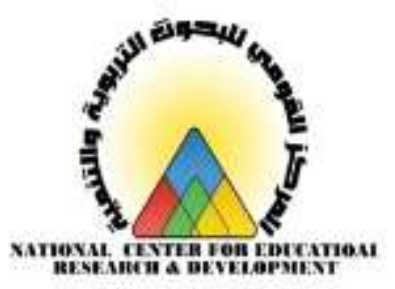

\title{
فاعلية استخدام بيئة تعلم إلكترونية في تنهية السعة العقلية لدى طلاب التعليم الثانوي الصناعي
}

\author{
إsld \\ حمدي أحمد صديق رشوان المراغي \\ باحث مساعد بالمركز القومي للبحوث التربوية والتتمية \\ تخصص مناهج وطرق تدريس تكنولوجيا التعليم
}

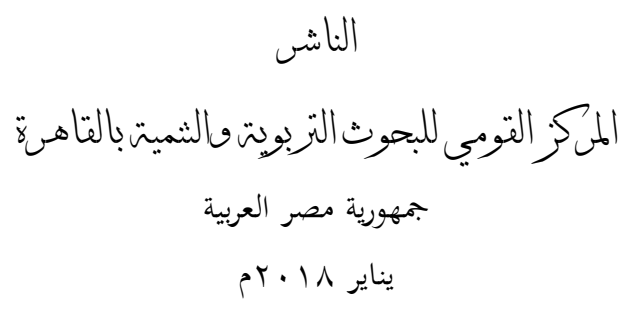




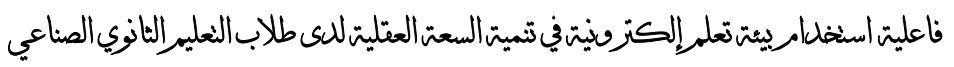

\section{فاعلية استخدام بيئة تعلم إلكترونية في تنمية السعة العقلية لدى طلاب التعليم الثانوي الصناعي \\ الباحث: حمدي أحمد صديق رشوان المراغي}

مستخلص البحث

هـدف البحث الحالي إلى: بحث فاعلية استخدام بيئة تعلم إلكترونية في تتمية

السعة العقلية لدى طلاب التعليم الثانوي الصناعي.

جهـة البحث: مديرية التربية والتعليم بمحافظة سوهاج - بمدارس (المحاسنة الثانوية الصناعية بنين - الفنية الصناعية بنات بجرجا - البلينا الثانوية الصناعية بنين

$$
\text { - الفنية الصناعية بنات بسوهاج). }
$$

ولتحقيق أهداف البحث نم بناء نموذج لتصــــيم بيئة نعلم إلكترونية، وبناء

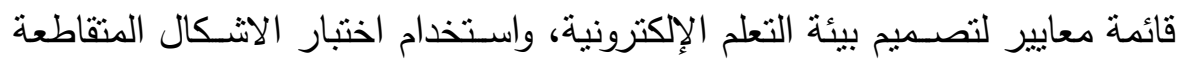
(السعة العقلية) لجان بسكاليوني. لئهئ.

وتكونت عينة البحث من (• \&.) طالب وطالبة من طلاب الصـــف الثالث الثانوي الصناعي بمدارس التطبيق بمحافظة سوهاج، وقسمت مجموعات البحث إلي

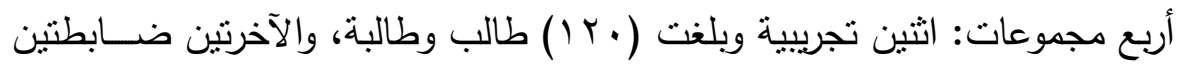

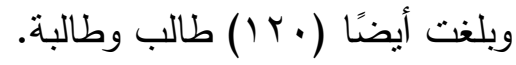

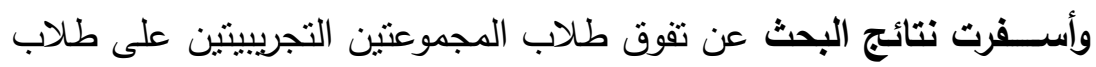

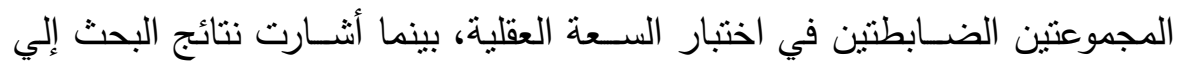
وجود فروق بين منوســـي درجات طلاب المجموعتين التجريبيتين ولكن غير دالة مهـا يدل على عدم وجود فرق بين طلاب المجموعـة التجرييية للبنين وطالبـات المجموعة التجريبية للبنات في السعة العقلية. الكلمات المفتاحية: بيئات التعلم الإلكترونية - السعة العقلية - التعليم الثانوي الصناعي. .$T \cdot T$. البحث التربوي 


$$
\text { المركن القومي للبحوث التبوبةوالنمية }
$$

\section{Effectiveness of Using an Electronic \\ Environment for Learning in Developing \\ Mental Capacity in Industrial Secondary School Students}

Researcher: Hamdy Ahmed Sdeek Rashwan El-mraghy

Study Title: The effectiveness use of an electronic learning environment in the development of the mental capacity of industrial secondary education students.

Study area: Directorate of Education in Sohag - Schools (Mahasna Secondary Industrial Boys - Industrial Industrial Girls Bjerga - Al-Balina Industrial Secondary Boys - Industrial Industrial Girls Sohag).

The objective of this research is to investigate the effectiveness of an electronic learning environment in the development of the mental capacity of industrial secondary education students.

To achieve the objectives of the research, a model was designed to design an e-learning environment, build a list of criteria for designing the e-learning environment, and use the cross-test (mental capacity) of the Pascalone committees.

The research sample consisted of (240) students from the third grade of industrial secondary school in Sohag governorate. The research groups were divided into four groups: two experimental and 120 students, the other two officers and 120 students.

The results of the study showed that the students of the two experimental groups were superior to the students of the two groups in the mental capacity test, while the results showed that there was no difference between the experimental group of boys and the experimental group of girls in the mental capacity test.

key words:

E-Learning Environment - Mental Capacity- Industrial Secondary Education. 


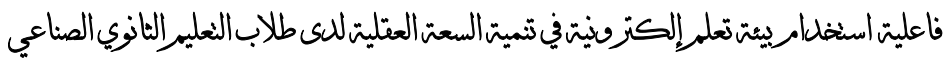

\section{فاعلية استخدام بيئة تعلم إلكتزونية \\ في تنمية السعة العقلية \\ لدى طلاب التمليم الثانوي الصناعي \\ إعـإl}

همدي أحمد صديق رشوان المر1 غي

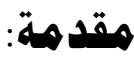

يشهد العالم تغير تكنولوجي سريع يحتم علينا حدوث تغيير في العملية التعليمية

لتقديم مخرجات تلبي احتياجات هذا التغير، وتعد شبكة الإنترنت من أهم الوسائل التكنولوجية الناجحة في تقديم المواد التعليمية عبر بيئات التعلم المختلفة التي يتم تصميمها بتتظيم وتتسيق واستخدام فعال للألوان والأشكال والرسوم والحركات والفيديوهات ... لعرض المعلومات بأساليب ممتعة أكثر من مرة حسب قدرات واحتياجات وسرعات واهتمامات وميول الطلاب في الحصول على المعلومات دون

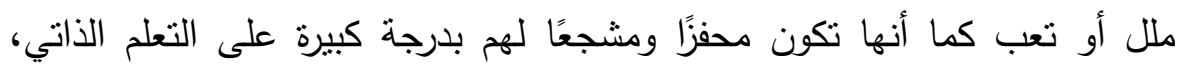
بالإضافة إلي إمكانية تفاعل المتعلم معها بشكل كبير يساعده على النحصيل والفهم

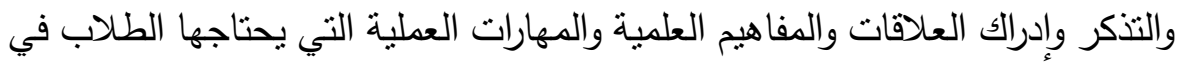
التعلم.

ونتيجة للتقدم العلمي والتطور التكنولوجي، لم يعد التعلم التقليدي بطرائقه التقليدية

التي تعتمد على المعلم في نقل المعرفة إلي التلاميذ قادراً على الوفاء بمتطلباته

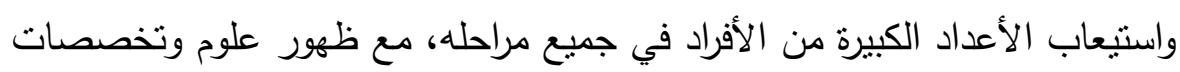

$$
\text { .r.人. }
$$

البحث التربوي 


\section{المركن القومي للبحوث التبويةوالتنمية}

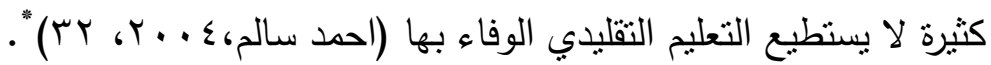
الأمر الذي يحتم علينا مواجهة هذه التحديات، والتعامل مع معطياتها، لتمكين الأجيال اللاحقة من العيش مواكبين لكل ما يحدث من متغيرات، وكذللك التعامل مع

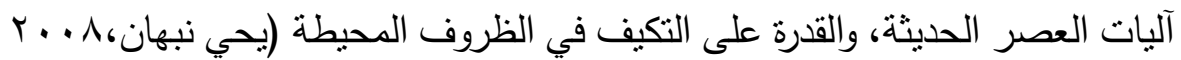
$\cdot\left(V^{7}\right.$ ،

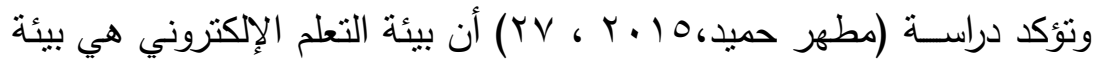

(تعليم/تعلم) إلكترونية حديثة، توظف تكنولوجيا التعليم والمعلومات والاتصــــالات

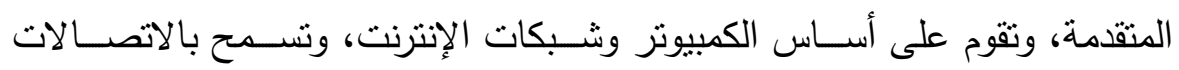

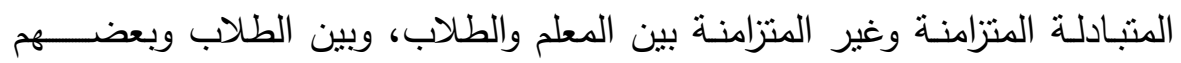
بعضًا، إذ يتيح استخدام بيئة التعلم الإلكتروني في التعليم مزايا عدة في مجملها تؤكد على قدرة هذه البيئة على ابتكار بيئات تعليمية غير تقليدية مما يجعل التعلم القائم

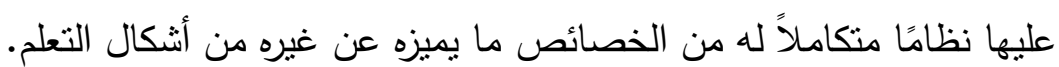
وتتميز البيئات التعليمية الإككترونية بأنها لا تحتاج إلى متخصص في البرمجة من أجل التعامل معها ولكنها نتطلب مجموعة من الكفايات التي يمكن تتميتها بسـهولة لدى مسـتخدمي هذه النظم، كما أنها توفر لوحة تحكم تســل عملية الإدارة، وتوفر وسـائل دعم منتوعة لكل من المتعلم والمدير والمطور والمعلم، وتتميز بسـهولة

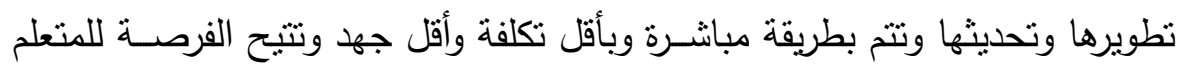
لاختيار مستوى التحكم الملائم لقدارته وإمكانياته، مما يساعده على التقدم في عملية تعلمة بسهولة (20) - Dorn \& Bhattacharay, 2007, pp.13).

* التوثيق وفقاً لاليل جمعية علم النفس الأمريكية (APA 6th ed)، بحيث يشير الرقم الأول إلى سنة

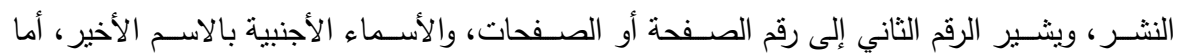

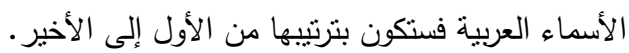
.9. 


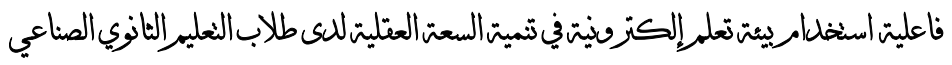

ولانعكاس اســتخدام التكنولوجيا على العمليات العقلية ترجع أهمية هذا البحث لتتمية الســـعات العقلية لدى الطلاب، والتي تســــاعدهم على فهم وتذكر المفاهيم العلمية المتعددة وخطوات حل المسـئل الهندسية المرتبطة بمقرر التركيبات الكهربية لتتمية جوانب القصسور في القدرات العقلية لطلاب التعليم الثانوي الصـناعي، وتوجيه انتباههم نحو استخدام بيئات تعلم إلكترونية في تتظيم وعرض المحتوى الدراسـي في وحدات ذات معنى يســل للطلاب معالجتها وفهمها وتذكرها في ضـوء اسـتعداداتهم العقلية مراعية الفروق الفردية بينهم.

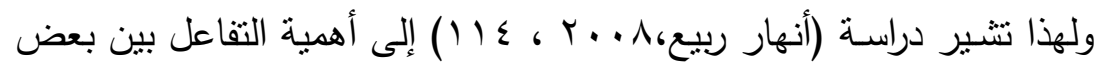
تصـميمات برامج الكمبيوتز متعددة الوسـائط وأسـلوب التعلم والسـعة العقلية لتتمية واكتساب مستويات تعلم المفاهيم العلمية. وأكدت دراسة (تامر متولي، V . . Y ، ـ 0) على أهمية الاستفادة من المستحدثات التكنولوجية والتي أصبحت محور الاهتمام من قبل الكثيرين، وذلك لأهميتها وطرق الاستفادة منها في العملية التعليمية مثل: أثر الواقع الافتراضي وعروض الفيديو كأحد أدوات التعليم الإلكتروني على السعة العقلية لاى طلاب تكنولوجيا التعليم. وتتير دراسة (إيهاب طلبة،91991 ، 79) إلى فاعلية استخدام إستراتيجية مقترحة في تتمية بعض القرات العقلية اللازمة لحل المسائل واختزال القلق الناتج عنها وعلاقة ذلك بالسعة العقلية لدى طلاب المرحلة الثانوية.

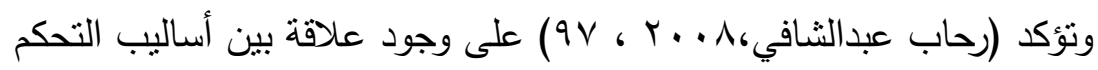
في برامج الكمبيوتز التعليمية ومستويات السعة العقلية للمتعلمين، وبين كفاءة التعلم لديهم.

ونظرًا لهذه التغيرات التي انبنقت مع دخول عصر المعلومات وثورة الاتصالات أصبح لزامًا على برامج التعليم الثانوي الصناعي بصفة عامة والمؤسسات الصناعية 


\section{المركن القومي للبحوث التبويةوالتنمية}

بصفه خاصة إعادة النظر في برامج التدريب، نظرًا لارنباطها الكبير بالثورة التكنولوجية، حيث يرجع أحد أسباب فنثل هذا النوع من التعليم إلي عدم وجود وسائل برأل توفر للمعلم والطالب المعلومة المرئية والمسموعة والمقروءة ومسايرة كل ما يحدث من

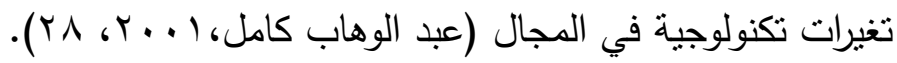

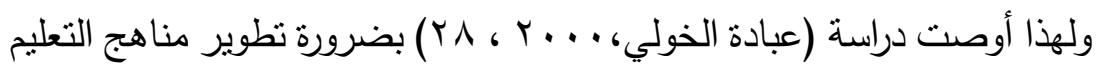

الثانوي الصناعي في ضوء نظرة نظامية متكاملة، مع دراسة شاملة لعلاقة التعليم الفني الصناعي بأنظمة المعلومات الحديثة وتطوراتها وتعديل التكنولوجيا التعليمية لتتناسب مع التغيرات في التكنولوجيا والمهن حتي يزداد الارتباط بين التعليم الصناعي والمهن السائدة في المجتمع. وتتاولت العديد من الدراسات والبحوث التربوية السعة العقلية وعلاقتها بالتحصيل

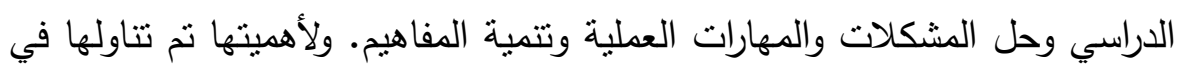
Lawson, 1983 ، Kenneth, 1980 (الدراسة وهذا يتفق مع دراسة كلٍ من ، Johnstone\& El - Banna, 1986 ، إسعاد البنا، وحمدي البنا، ل 199

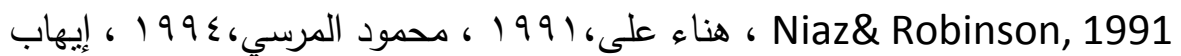

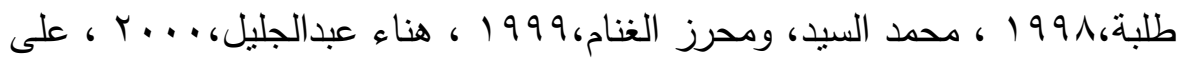

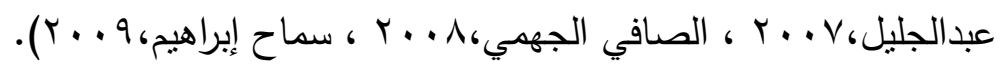
وكذلك أكدت العديد من الدراسات السابقة أهمية استخدام الوسائط المتعددة إيرهات والفائقة والإنترنت مع الطلاب ذوي السعات العقلية المختلفة لتتمية التحصيل وتعلم

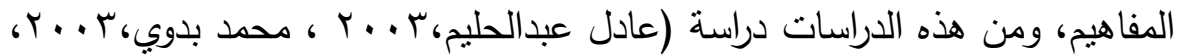

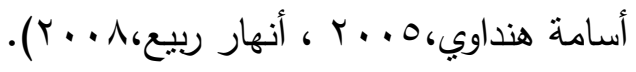

ويتضح مما سبق ضرورة إعادة النظر في طرق تدريس مقرر التعليم الفني وخاصتًا مقرر "التركيبات الكهربية" بالتعليم الصناعي والبحث عن وسائل وطرق 
تدريس تكنولوجية حديثة، نظراً لطبيعة المحتوى العلمي الذي يحتاج إلي تفاعل الطالب معه ومشاهدته وممارسته للعديد من المهارات العملية حسب مستويات وظروف كل طالب بشكل مستمر للوصول إلي المعارف والمعلومات والمهارات اللازمة لإشباع حاجة الطلاب وزيادة قدراتهم العلمية والعملية، ولهذا يقترح الباحث استخدام بيئة نعلم إلكترونية في تدريس مقرر (التركيبات الكهربية) لتتمية السعة العقلية لاى طلاب التعليم الثانوي الصناعي.

\section{وقد أحس الباحث بمشكلة البحث من خلال ما يلي:}

متابعة الباحث التدريس بالمدارس الفنية الصناعية حيث لاحظ استخدام طرق تدريس تقليدية في دراسة مقرر (التركيبات الكهربية) بالصف الثالث الثانوي الصناعي.

المقابلات والمناقثنات التي أجراها الباحث مع عدد من معلمي التعليم الثانوي الصناعي الذين أثناروا إلي أن طريقة تقديم وتدريس محتوى مقرر "التركيبات الكهربية" لا تراعي الفروق الفردية والاحتياجات الفعلية وظروف وإمكانيات واحتياجات طلاب التعليم الثانوي الصناعي. استطلاع الرأي الذي أجراه الباحث مع عدد من معلمي المدارس الثانوية الصناعية بجرجا، والتي أثنارت إلي ما يلي: - عدم توافر وسائل وطرق تدريس حديثة تساعد الطلاب على تحقيق أهداف التعليم الصناعي التي تربطهم بسوق العمل وتسمح لهم بمواكبة التطورات الحديثة في التخصص.

- عدم تحقيق أهداف مقرر التركيبات الكهربية لاستخدام طرق تقليدية غير فعالة في تقديمه. - عدم توافر الوقت الكافي داخل الحصة لعرض كل ما يحتويه مقرر "التركيبات 


\section{المركن القومي للبحوث التبويةوالتنمية}

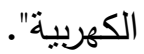

- عدم قدرة الطلاب على فهم المفاهيم وإدراك العلاقات بين المعلومات ومعالجة المعلومات لتذكر واسترجاع هذه المعلومات المنضمنة بمقرر "التركيبات الكهربية" الأمر الذي أثنار إلي ضعف الذئف الذاكرة لدى الطلاب.

- عدم قدرة الطلاب على التفاعل مع المقرر والتواصل مع المعلم.

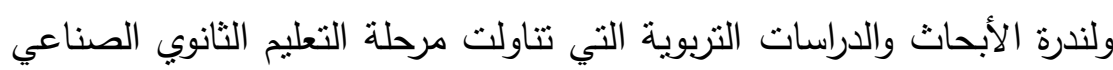
مقارنةً بمراحل التعليم الأخرى- على حد علم الباحث وخاصة التي استخدمت بيئات التعلم الإكترونية، يسعي الباحث لتوظيفها في هذا البحث لتخلب على المشكلات التي تواجه الطلاب وتسهيل عملية التعلم في أي وقت وأي مكان متصل بالإنترنت لتتمية السعة العقلية وذلك بما يتفق مع طبيعة ومحتوى مقرر "التركيبات الكهربية"، وهذا ما بالاتسية دفع الباحث لإجراء هذا البحث لفتح الطريق أمام الباحثين التربوبين لإجراء دراسات أخرى ذات علاقة بمناهج التعليم الثانوي الصناعي.

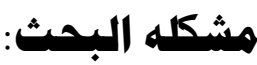

تكمن مشكلة البحث الحالي في انخفاض مستوى السعة العقلية، وهذا استتادًا إلي ما تقدم من نتائج المقابلات والمناقتات واستطلاع الراي الذي قام بها الباحث مع عدد من معلمي وطلاب التعليم الفني الصناعي، وهذا دعى الباحث لاستخدام بيئة التعلم الإلكترونية، في محاولة لتغلب على هذه المشكلة ومواكبة التطورات التكنولوجية

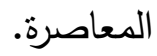

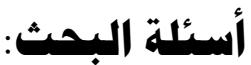

يحاول البحث الحالي الإجابة عن السؤال التالي: - ما فاعلية استخدام بيئة التعلم الإكترونية القائمة على الحوسبة السحابية في שו 


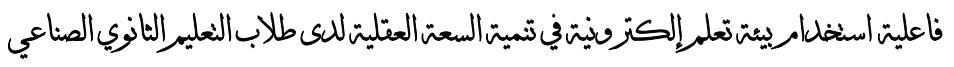

تدريس مقرر التركيات الكهربية لتتمية السعة العقلية لدى طلاب التعليم الثانوي

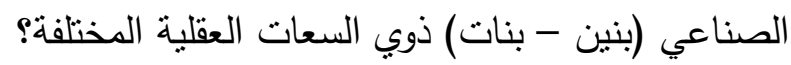

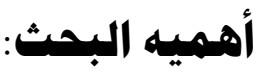

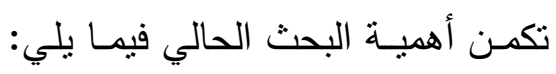

1. إلقاء الضوء على أهمية استخدام بيئات التعلم الإكترونية في التدريس للارتقاء

بعملية التعليم والتعلم وزيادة فاعليتها.

r. تقديم دليل إلكتروني للطالب للتعلم من خلال بيئة التعلم الإلكترونية، لتسهيل

عملية التعليم والتعلم ومواكبة التقام في هذا المجال.

r. قد تساعد في التظلب على المشكلات الحالية في تدريس مقرر "التركيات

الكهربية" وما يشوبها من سلبيات.

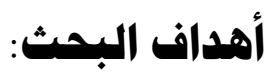

يهـدف البحث الحالي إلي بحث فاعلية استخدام بيئة تعلم إلكترونية في تتمية

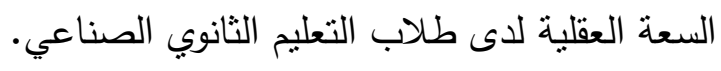

هدود البحث:

تتمثل حدود البحث الحالي فيما يلي:

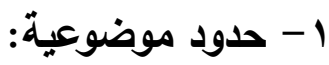

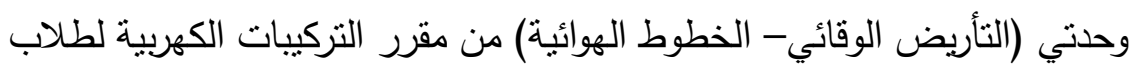

الصف الثالث الثانوي الصناعي، التعرف على مسنويات السعة العقلية (مرتفع -

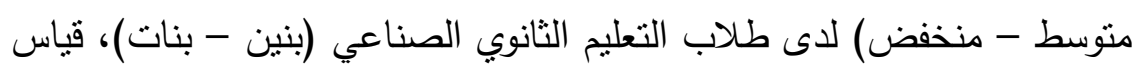

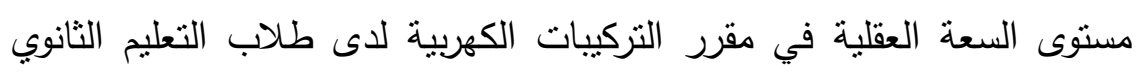

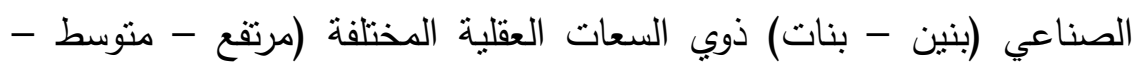




\section{المركن القومي للبحوث التبويةوالتنمية}

$$
\text { r منخفض) - حدود زمنية: }
$$

تطبيق تجربة البحث الميداني في الفصل الدراسي الأول من العام الدراسي

$$
\begin{aligned}
& \cdot(r+1) / r \cdot 1 T) \\
& \text { r- حدود مكانية }
\end{aligned}
$$

تطبيق إجراءات البحث الميدانية على مجموعات البحث الآتية:

ه المجموعة الأولي "الضابطة" من معلمة البلينا الثانوبة الصناعية بنين. • المجموعة الثانية "الضابطة" من معلمة الفنية الصناعية بنات بسوهاج. ه المجموعة الثالثة "التجربيية" من معلمة المحاسنة الثانوية الصناعية بنين. • المجموعة الرابعة "التجربيية" من معلمة الفنية الصناعية بنات بجرجا.

اعتمد البحث الحالي على المنهج الوصفي لوصف وتحليل الأدبيات والبحوث والدراسات السابقة المتعلقة بمتغيرات البحث الحالي، والمنهج التجريبي لبحث فاعلية بيئة تعلم إلكترونية في تدريس وحدتي البحث في تتمية السعة العقلية لدى

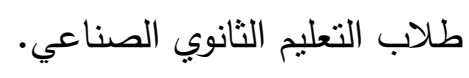

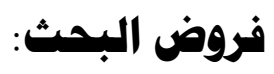

للإجابة عـن سؤال البحث تـم صباغــة الفـروض الأتبـة:

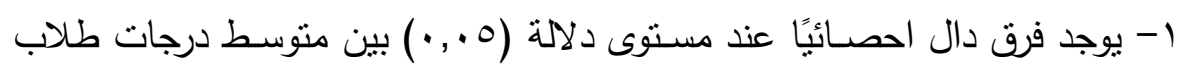
المجموعة التجريبية بنين (ذوي الســعات العقلية المختلفة) الذين درســوا وحدتي الدراســــة (التأريض الوقائي - الخطوط الهوائية) من مقرر التركيبات الكهربية باستخدام بيئة التعلم الإككترونية القائمة على الحوسبة السحابية ومتوسط درجات طلاب المجموعة الضـابطة بنين (ذوي السـعات العقلية المختلفة) الذين درسـوا M 10 . 


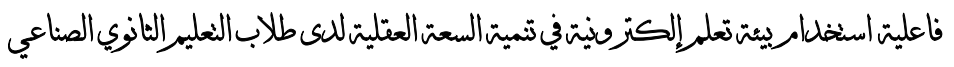

نفس المحتوى بالطريقة التقليدية العادية وذلك في التطبيق البعدي لاختبار السعة العقلية، وهذا الفرق لصالح درجات طلاب المجموعة التجريبية.

r- يوجد فرق دال احصـائًاً عند مسـتوى دلالة (0 ., •) بين متوسط درجات طلاب

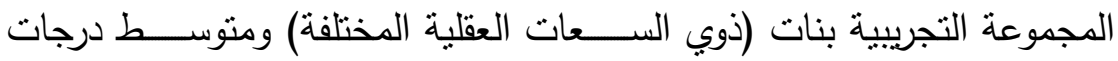
طلاب المجموعة الضـــابطة بنات (ذو الســعات العقلية المختلفة) في التطبيق البعدي لاختبار الســعة العقلية، وهذا الفرق لصـــالح درجات طلاب المجموعة التجريبية.

ب- يوجد فرق دال احصـائًا عند مسـتوى دلالة (0. . ·) بين متوسـ درجات طلاب المجموعة التجريبية بنين (ذوي السعات العقلية المختلفة) ومتوسط درجات طلاب المجموعة التجريبية بنات (ذوي الســـعات العقلية المختلفة) في التطبيق البعدي لاختبار السـعة العقلية، وهذا الفرق لصــالح درجات طلاب المجموعة التجريبية

بنين.

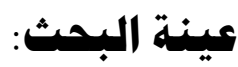

تم اختيار مجموعات البحث من طلاب الصف الثالث تخصص (تركيبات كهربية) بالتعليم الثانوي الصناعي (بنين - بنات) بمدارس التطبيق بمحافظة سوهاج.

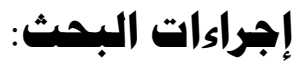

ا ـ الاطلاع على الأبحاث والدراسات السابقة والأدبيات التربوية المرتبطة بتصميم بيئات تعلم إلكترونية للاستفادة منها في إعداد الجزء النظري لهذا البحث وأدواته. r. الاطلاع على الأبحاث والدراسات السابقة والأدبيات التربوبة المرتبطة بمتغيرات

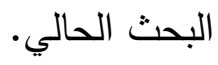

r. إعداد قائمة معايير بيئة التعلم الإلكترونية وضبطها. ء. تصميم بيئة تعلم إلكترونية وفقاً للنموذج المفترح والأهداف السلوكية للمقرر .TI7. 


\section{المركن القومي للبحوث التبويةوالتنمية}

وعرضها على مجموعة من السادة المحكمين لضبطها "إعداد الباحث". 0. استخدام اختبار الأشكال المتقاطعة (اختبار السعة العقلية) لجان بسكاليوني لقياس السعة العقلية لدى طلاب مجموعات البحث. 7. اختيار مجموعات البحث الضابطة والتجريبية (بنين - بنات). V. إجراء التطبيق القبلي لاختبار السعة العقلية على طلاب مجموعات البحث الضابطة والتجريبية (بنين - بنات) عينة البحث.

^. تتفيذ تجربة البحث حيث تم تدريس وحدتي البحث من خلال بيئة التعلم الإلكترونية للمجموعتين التجريبيتين، وتدريس وحدتي البحث للمجموعتين الضابطتين بالطريقة

$$
\text { 9. التطبيق البعدي لأدوات البحث. }
$$

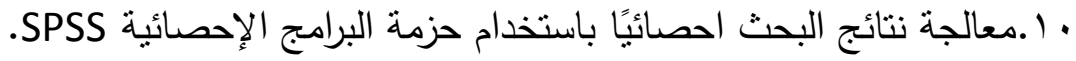
1 ( ا.تفسير ومناقتة النتائج، وتقديم ملخص وتوصيات ومقترحات البحث.

\section{همطاتحات البمث:}

\section{* بيئة التعلم الإكترونية Electronic Learning Environment:}

عرفها (عبدالعزيز طلبة، • 1 ـ ، ، 9 ؛ ) بأنها "بيئة مرنة للتعلم بلا أرض أو جدران أو أسقف تتخطى حدود الزمان والمكان يجلس فيها الطلاب أمام أجهزة الكمبيوتر في بـاني مدارسهم أو منازلهم أو أي مكان يدرسون مقررات مبرمجة على الكمبيوتز أو من خلال مواقع الإنترنت ويتصلون بأساتذتهم بشكل منزامن أو غير منزامن للحصول على الحوار والمصادر والمعلومات وغيرها، ويتفاعلون مع أساتذتهم وزملائهم". ولغرض هذا البحث يمكن تعريف "بيئة التعلم الإلكترونية" إجرائيًا بأنها: بيئة يتعلم الطلاب من خلالها في أي مكان منصل بالإنترنت دون قيود لزمان

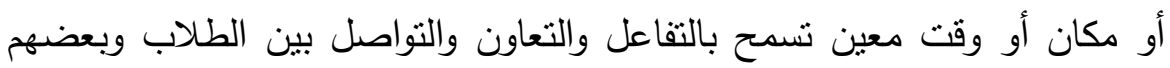




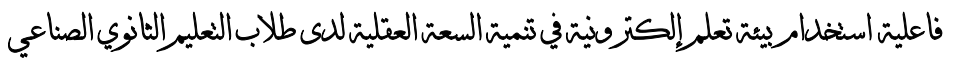

البعض وبين الطلاب والمعلم في أي وقت عبر الحوسبة السحابية.

Mental Capacity السعة العقلية * ائل

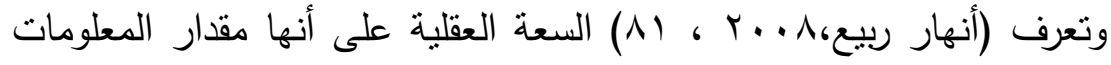

التي تستطيع الطالبة ترتيبها وتتظيمها وتجميعها في ذاكرتها والتعامل معها أثناء اكتسابها لمستويات تعلم المفاهيم العلمية المقدمة لها وتقاس باختبار الأشكال المنقاطعة ولهية

لجان باسكاليوني.

ولغرض هذا البحث يمكن تعريف "السعة العقلية" إجرائيًا بأنها: قدرة الطالب على معالجة وتتسيق وتتظيم المعلومات والمفاهيم العلمية التي تقدم له من خلال برامج الحاسوب عبر الشبكة العنكبوتية بشكل بيسمح له بزيادة كفائتة

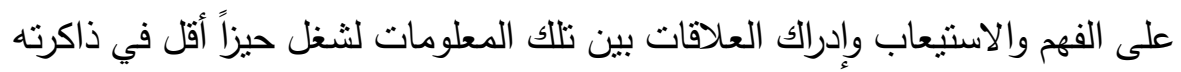
بشكل يؤدي إلى نتائج أفضل في الأداء. أولاً: أدوات البحث يؤي إلى ل... وتمثنلت في: > تصمبم وبناء بيبئة التهلم الإلكترونبة:

وإنباع الباحث الخطوات التالية عند تصميم وبناء بيئة التعلم إلكترونية: I ـ إعداد قائمة معاييز التصميم:

أعتمد الباحث في بناء قائمـة المعايير على تحليل الأدبيات التربوية، ونتائج الدراسـات والبحوث السـابقة المتخصصـة في تكنولوجيا التعليم وخاصـة التصميم

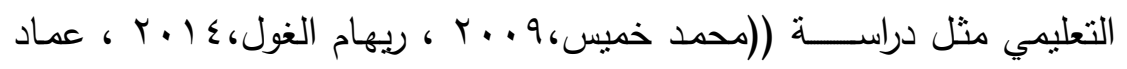

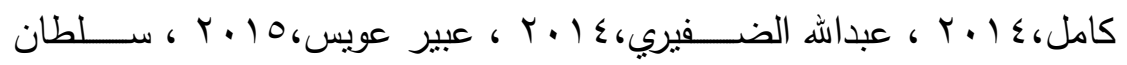

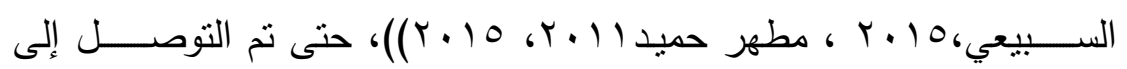
مجموعة من المعايير ولكل معيار مجموعة من المؤشرات الدالة علية وفيما يلي عرض المعايير الرئيسة التي تم التوصل إليها: . البحث التريوي 


\section{المركن القومي للبحوث التبويةوالتنمية}

1- تتظيم الصفحة الرئيسة في بيئة التعلم الإكتروني. r- تحديد الأهداف داخل كل درس في بيئة التعلم الإكتروني. r- تحديد المحتوى داخل صفحات بيئة التعلم الإلكتروني. ع- تتظيم وتتسيق المحتوى داخل صفحات بيئة التعلم الإلكتروني. 0- كتابة المحتوى داخل صفحات بيئة التعلم الإلكتروني. 7- مصادر التعلم في بيئة التعلم الإكتروني. - V توظيف الأنشطة التعليمية بكفاءة داخل بيئة التعلم الإلكتروني. - أسئلة التقويم في بيئة التعلم الإككتروني. 9- دليل الطالب التعليمي في بيئة التعلم الإككتروني. • 1- مصداقية بيئة التعلم الإلكتروني. 11- تخطيط صفحات بيئة التعلم الإلكتروني. r ا - تنظيم العناوين في بيئة التعلم الإلكتروني. ץ ا- الخطوط والمسافات داخل بيئة التعلم الإلكتروني. ع ا- الألوان في بيئة التعلم الإلكتروني. 10- الصور والرسومات داخل بيئة التعلم الإلكتروني. 7 ا 17 IV 11 - تصفح بيئة التعلم الإلكتروني وسرعة التحميل. 9 1 - التفاعل والتغذية الراجعة في بيئة التعلم الإكتروني.

• r- توظيف أدوات المساعدة والتواصل عبر الحوسبة السحابية بكفاءة داخل بيئة التعلم. ا Y- توظيف الإستراتيجيات التعليمية بكفاءة داخل بيئة التعلم الإلكتروني. 


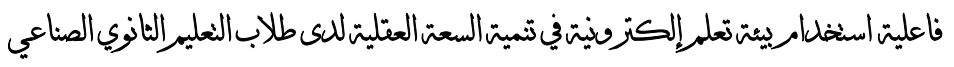

r r- تحكم المستخدم في خيارات بيئة التعلم الإكتروني. بr- الروابط المتشعبة Hyper Links في بيئة التعلم الإلكتروني.

$$
\text { ع الاخت الاختبار في بيئة التعلم الإكتروني. }
$$

\section{القائمة في صورتها الأولية:}

تم عرض قائمـة المعايير والمؤثـــرات على مجموعة من الســــادة المحكمين

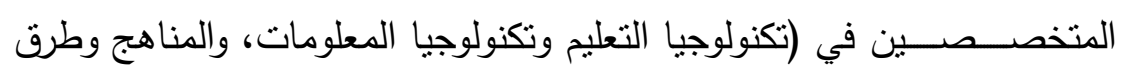
تدريس التعليم الصـــناعي بالجامعات والكليات التكنولوجية) وطلب منهم إبداء

$$
\text { آرائهم فيها من حيث: }
$$

- مدى سلامة الصياغة اللغوية والعلمية.

- مدى مناسبة المؤسر للمعيار الذي ينتمي له. - مدى

- مدى اهمية المعيار والمؤشرات.

- مدى صلاحية المعايير والمؤشرات للنطبيق.

- إضافة أي ملاحظات أو مقترحات من السادة المحكمين.

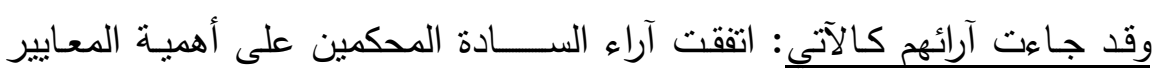

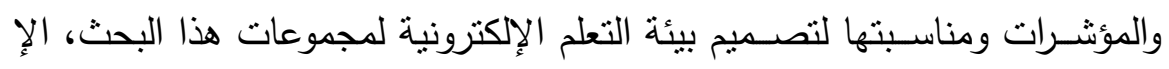

$$
\text { أنهم أثشاروا إلى ما يلي : }
$$

- مؤشرات تعدل الصياغة اللغوية والعلمية لها.

- معايير ومؤشرات ثبقى كما هي دون الحذف أو التعديل.

- معايير تدمج لتكرار نفس الهدف منها في معيار أخر -

- إعادة ترتيب بعض المعايير وفقًا لخطوات التصميم.

- مؤشرات تحذف لتكرار نفس الهدف منها مع معيار أخر .

- مؤشرات تحذف لعدم مناسبتها للهدف أو المعيار .

$$
\text { .r. }
$$




\section{المركن القومي للبحوث التبويةوالتنمية}

وقام الباحث بإجراء التعديلات التي أثنار إلية السادة المحكمين حتى أصبحت قائمة المعايير والمؤشرات جاهزة في صورتها النهائية. قائمة المعايير والمؤشرات في صورتها النهائية: بعد إجراء التعديلات التي أثنسار إليها السـادة المحكمين تم التوصل إلى الصسورة النهائية لقائمة معايير ومؤشرات تصميم بيئة التعلم الإلكترونية. r. إعداد نموذج التصميم التعليمي المقترح لبيئة التعلم الإكترونية:

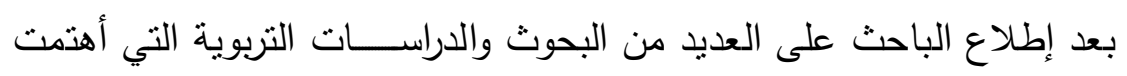

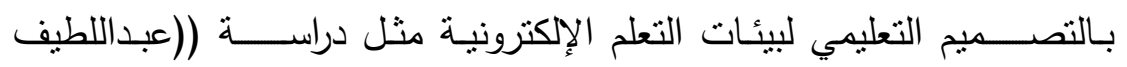

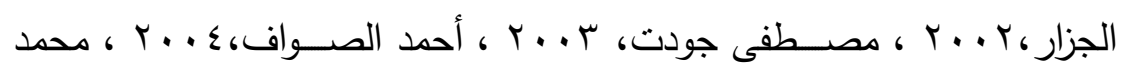

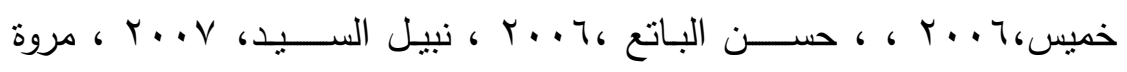

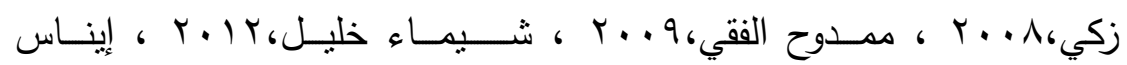

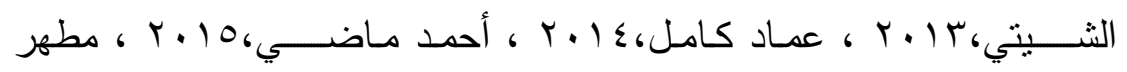

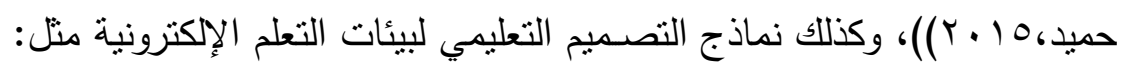

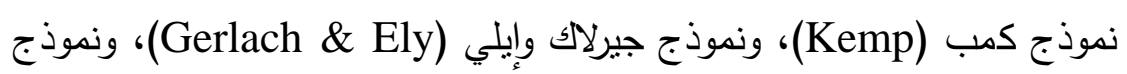

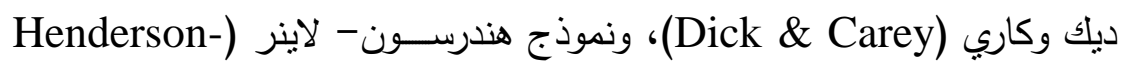
(Liner

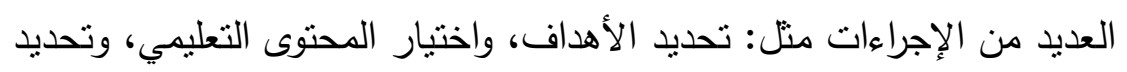

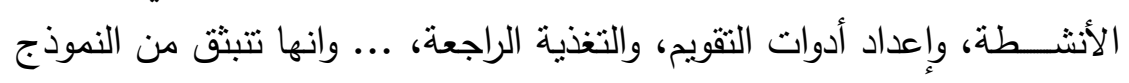

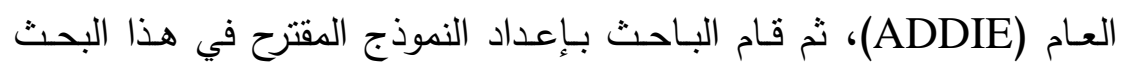

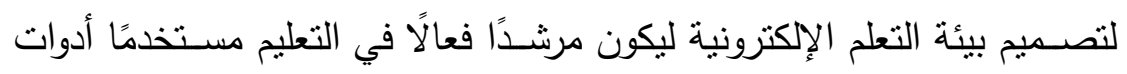

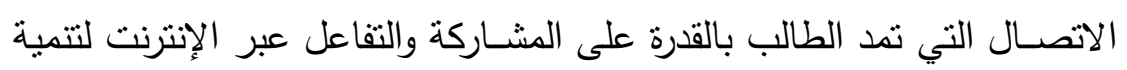
السعة العقلية.

أ- أهمية النموذج المقترح: العفية 
عند تصـميم بيئة التعلم الإلكتروني لابد من وجود نموذج يعتمد علية المصـمم في

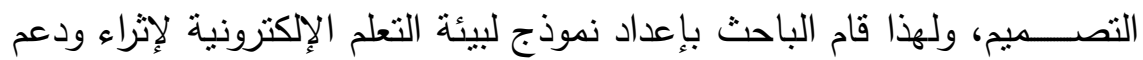

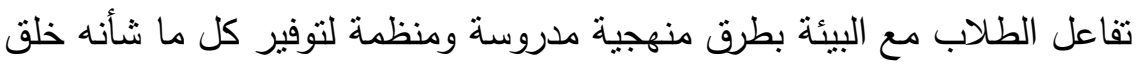

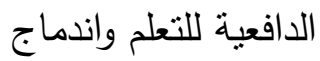

\section{اللهدف من النموذج المقترح:}

يتمثل الهدف الرئيسي لإنشـاء وبناء النموذج المقترح لتصـيم بيئة تعلم إلكترونية فيما يلي:

تقديم تصور مقترح لمراحل تصميم وإنشاء بيئات التعلم الإكترونية. تقديم نموذج جديد متضــناً خطوات تفصـيلية واضـحة لتصـميم وإنثـاء بيئات التعلم الإككترونية بالمعايير اللازمة لإنشائها وبرمجة صفحاتها باستخدام لغات

برمجة تفاعلية.

وضـع أسسس عامة وقواعد ثابتة لمسـاعدة القائمين على تصـميم وبناء بيئات

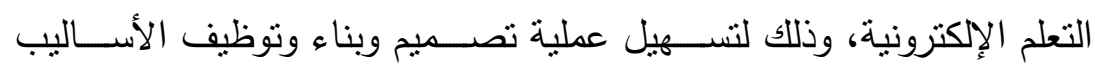
والاستراتيجيات المناسبة في هذه البيئات.

مسـاعدة المصـمم التعليمي في مدارس التعليم الصـناعي والكليات التكنولوجية في تصميم وإنشاء بيئة تعلم إلكترونية في ضوء في عدد من الخطوات البسيطة. تقديم نموذج في التصميم التعليمي بمجال التعليم الصناعي والتكنولوجي. لهي. ج- مكونات النموذج المقترح: يتكون النموذج المقترح في هذا البحث من ســـت مراحل رئيســة هي: ((مرحلة

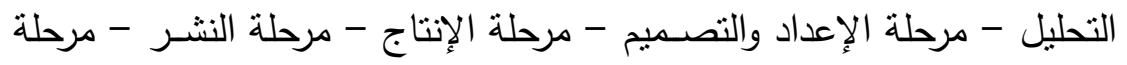

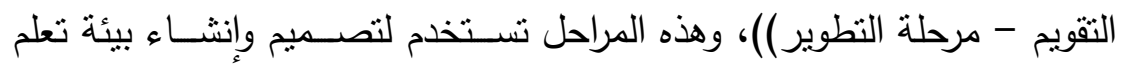
إلكترونية بما يتتاسب مع خصائص وإمكانيات وقدرات واحتياجات طلاب التعليم

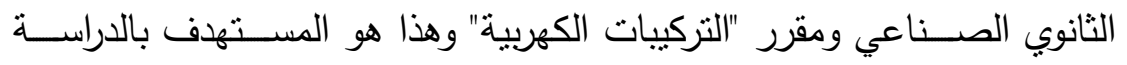




$$
\text { المركن الثومي للبحوث التبويةوالنمية }
$$

الحالية، وقد تم عرض هذا النموذج على مجموعة من الســادة المحكمين لإبداء آراء سيادتهم فيه حتى أصبح النموذج في صورته النهائية كما يلي:

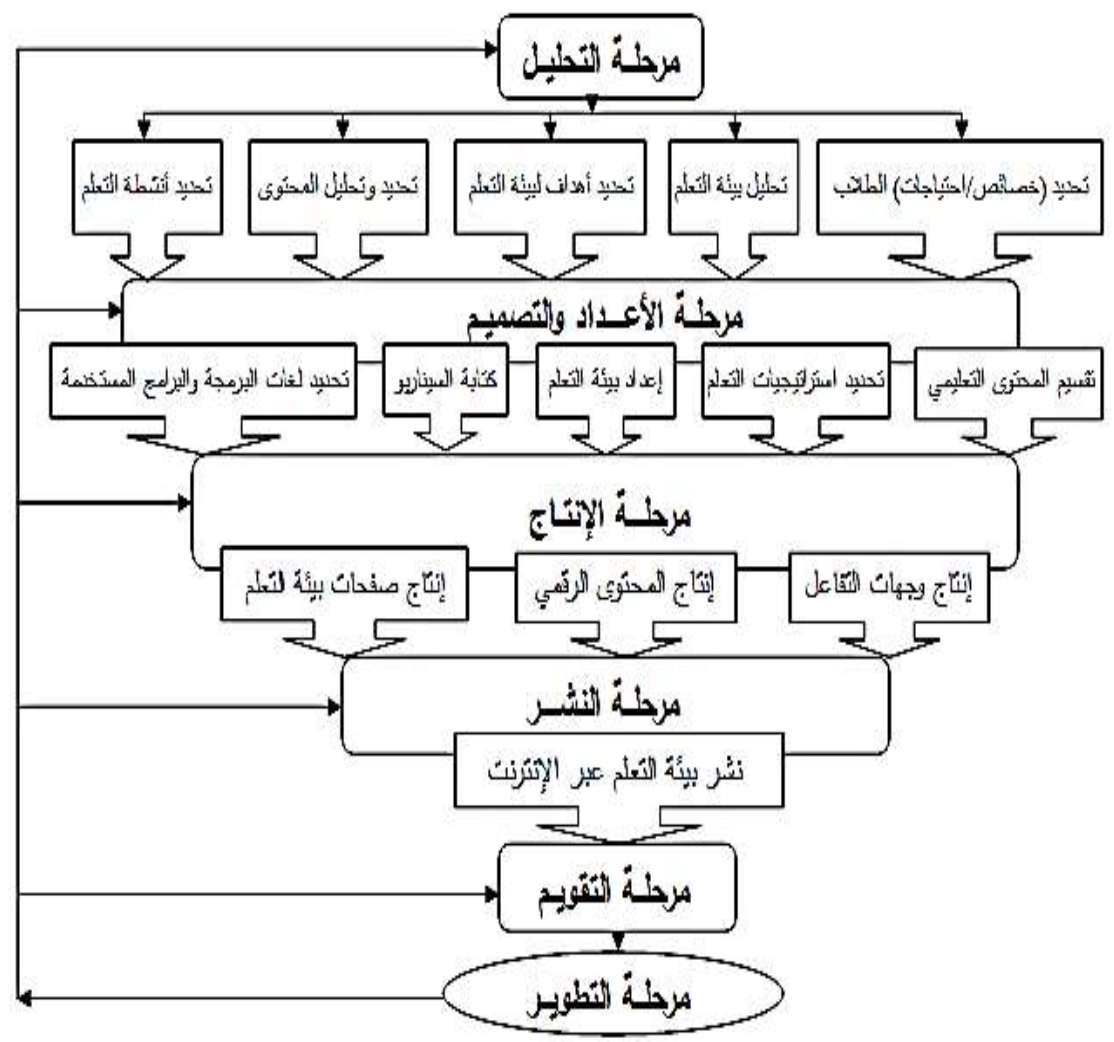

شكل (1)

نموذج التصميم التعليمي المقترح لتصميم بيئة التعلم الإلكترونية

• عرض بيئة التعلم على السادة المحكمين: . 
قام الباحث بتصـميم بيئة التعلم الإلكترونية في ضـوء النموذج المقترح، وعرضـها على مجموعة من السادة المحكمين المتخصصين الذين أشناروا إلي: - عمل خلفيات مختلفة للبنر نتير إلى محتوى الوحدتين وهدف البيئة. - التغيير والتعديل في بعض العبارات بالصفحة الرئيسة. - إضافة إمكانية تعلم الطالب بشكل (خطي/ تشعبي) داخل الدروس. - تعديل مسمى قائمة دليل الطالب إلى دليل مهارات التعلم. - عمل باس ورد مختلف للتقويم داخل كل درس من الدروس عبر البيئة. - عمل بعض التعديلات الأخرى الخاصة بالأهداف.

ه المجموعة الاســنطلاعية للطلاب: بعد الانتهاء من عمل كافة التعديلات بناءً على آراء السـادة المشـرفين والمحكمين أصـبحت بيئة التعلم الإلكترونية جاهزة، حيـث قـام البـاحـث بعرض بيئة التعلم الإلكترونيـة من خلاء الرابط التـالي: عـلى طـلاب الـــــــــ//drhamdy-clouds.16mb.com) الاستطلاعية الذين أثناروا إلى ما يلي: - تكبير خط بعض النصوص والصور غير الواضحة. - تغيير بعض الألوان غير المناسبة.

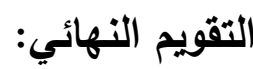

قام الباحث بعمل جميع التعديلات التي أوصـــت بها المجموعة الاســتطلاعية والســادة المحكمين، حتى أصسـبحت بيئة التعلم الإلكترونية جاهزة للاســتخدام http:/drhamdy-) والتطبيق على مجموعات البحث من خلا الرابط التالي: .(clouds. $16 \mathrm{mb}$.com 


\section{المركن القومي للبحوث التبويةوالتنمية}

Figure Intersection Test (F.I.T) تم استخدام اختبار الأشكال المتقاطعة ، وهو اختبار (ورقة وقلم - جمعي)، حيث قام بتصــــيمه عالم النفس الكندي "جان باسـكإللوني Pascual-leone Juan " عام Vד 9 (م، واسـتخدمته العديد من الدراســات التربوية منل دراسـة (إسـعاد البنا، وحمدى البنا، ، 99 1 ، عادل سـرايا،1990 ، محمد على، ومحرز الغنام،1999 ، محمد سـعودي، ... ب ، Dejowski,E., ، · . . Gerrig\& Zimbardo, 2002 2003 ، حمــدى البنا، وأسامة هنداوي، ه . . ب ، Levre, j., et al, 2005

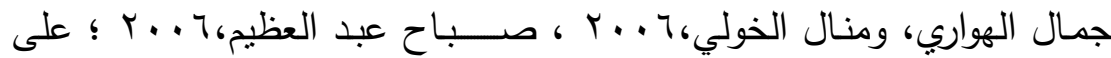

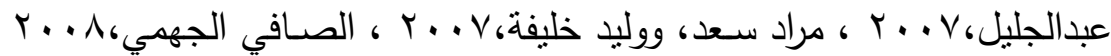

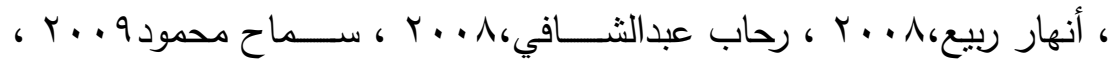

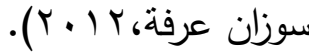
أ- الهدف من الاختبار:

نهدف من اختبار الأثــكال المتقاطعة قياس السـعة العقلية لدى طلاب التعليم الثانوي الصـناعي، وقد قام (حمدى البنا، وإسـعاد البنا، ـ 99 ( ) بترجمته وإعداده باللغة العربية، وحساب صدقه وثباته على البيئة المصرية، وقام الباحث بتقنينه على طلاب التعليم الثانوي الصناعي، نظرًا لما يتميز به الاختبار من كفاءة في قياس السعة العقلية.

\section{ب- وصف اختبار السعة العقلية:}

يتكون الاختبار من (ד شــكلاً) بالإضــافة إلى (ب أثــكال تمهيدية "أمثلة")، حيث يتكون كل بند من بنود الاختبار من مجموعتين من الأثـــال الهندســية Presentation البسيطة: مجموعة في الجهة اليمنى وتسمي مجموعة العرض ، Test Set Set ، ومجموعة في الجهة اليسرى وتسمي بالمجموعة الاختبارية ، 


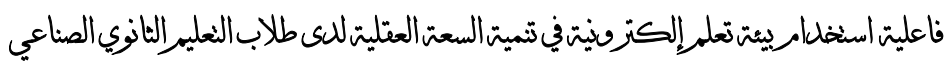

وتحتوي مجموعة العرض على عدد من الأثــــال المختلفة كل شــــل منها

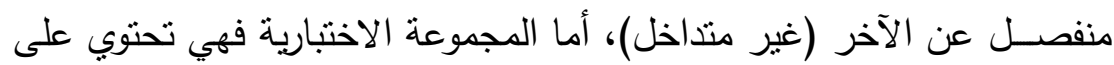
نفس الأشكال الموجودة في مجموعة العرض ولكنها مرتبة بشكل متداخل بحيث

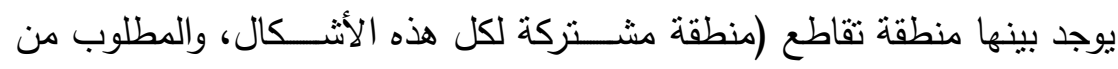
المفحوص تظليل هذه المسـاحة المشـتركة بين هذه الأشـكال)، والجدول التالي يوضح مثال على ذلك:

جدول (1) (1) (1) (1)

مثال على أسئلة اختبار السعة العقلية

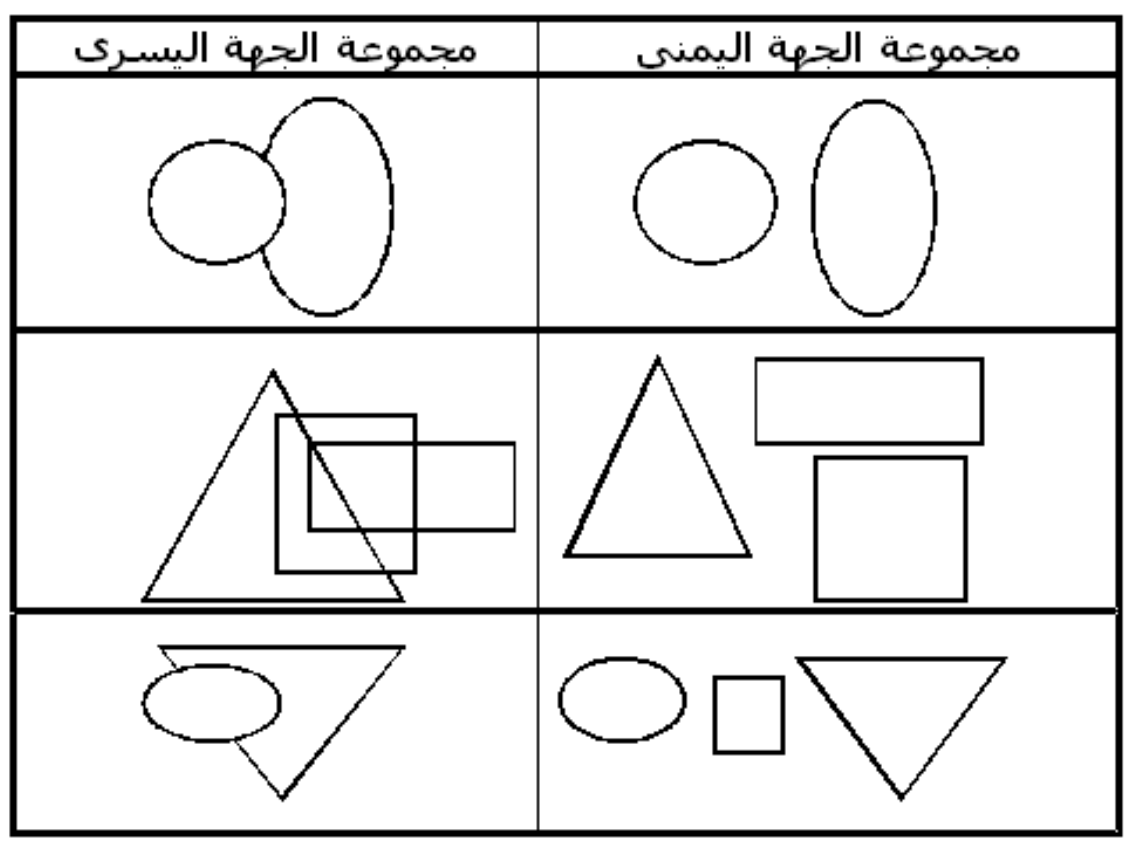

.

البحث التريوي 


\section{المركن القومي للبحوث التبويةوالتنمية}

ويتراوح عدد الأثــــكال الموجودة في مجموعة العرض من ب إلى ^ أثنـــكال، وبزيادة عدد الأشـكال في كل بند من بنود الاختبار تزداد صـعوبة إيجاد منطقة

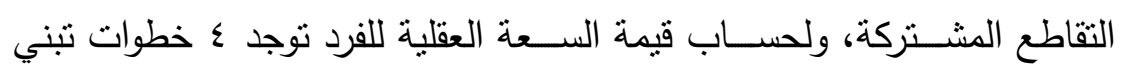
أسـاستًا على فروض نظرية باسـكاليوني للعامل العقلي M (حدي البنا، وإسـعاد البنا، • 999 | "اختبار الأشكال المتقاطعة").

\section{ج- وضع تعليمات الاختبار:}

تم وضـــع تعليمات الاختبار التي توضـــح للطالب الهدف من الاختبار ونوعية أسئلته وكيفية الإجابة عليها، وتوجيه الطالب للإجابة عن جميع أسئلة الاختبار وأهميه الدقة في تحديد الإجابة على الثكل، وبعد صباغة تعليمات الاختبار تم وضعها في الصفحة الأولى للاختبار بعد بيانات الطالب. دـ عرض اختبار السعة العقلية على السادة المحكمين:

قام الباحث بعرض اختبار الأثـــكال المتقاطعة الذي يتكون من (بس شــــالًا)

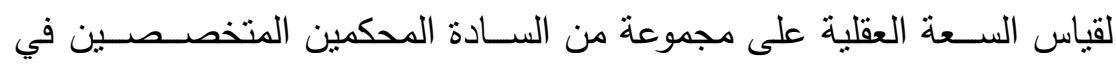
مجـال ((علم النفس، والمنـاهج وطرق التـدريس، وتكنولوجيـا التعليم، والتعليم الصناعي)) وذلك بهدف التأكد من: - وضوح تعليمات الاختبار • - دقة ووضوح الأشكال الموجودة بالاختبار • - ملائمة الاختبار لقياس السـعة العقلية لدى طلاب الصــف الثالث بالتعليم الثانوي الصناعي. وقد جاءت آراء الســادة المحكمين متفقة من حيث صــدق الظاهري للاختبار ، حيث أن أسئلة الاختبار تقيس ما وضعت لقياسه ومناسبة وملائمة لقياس السعة 
العقلية لاى طلاب التعليم الثنانوي الصناعي، وبذلك أصبح الاختبار يتكون من

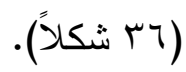

هـ - التجرية الاستطلاعية للاختبار:

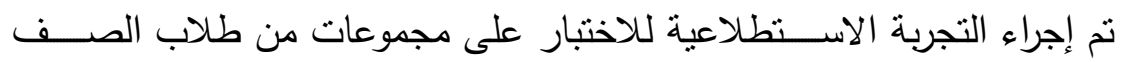

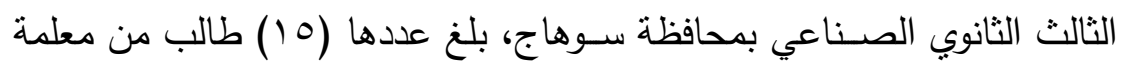
المحاسنة الثانوية الصناعية بنين، (10) طالبة من معلمة الفنية الصناعية بنات

$$
\text { بسوهاج، وتم النطبيق الاستطلاعى بهدف: }
$$

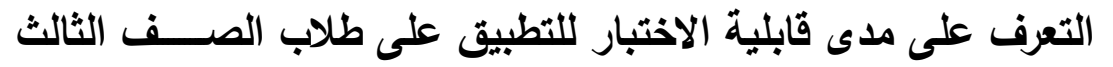

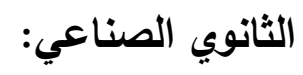

فلم توجد أي مشكلة أو شكوى من الطلاب والطالبات أثناء تطبيق اختبار السعة العقلية.

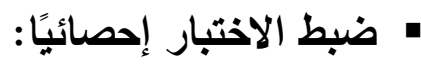

للتحقق من مدى التجانس الداخلي للاختبار ومدى الصدق والثنات، وذللك من خلال

$$
\text { - صدا يلي: الاختبار: }
$$

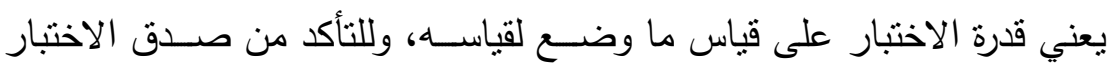

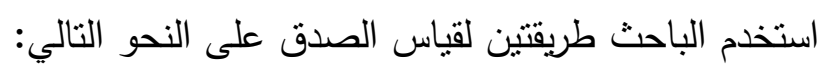

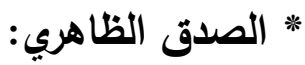

تم التأكد من الصـدق الذاتي للاختبار عن طريق عرض اختبار السـعة العقلية

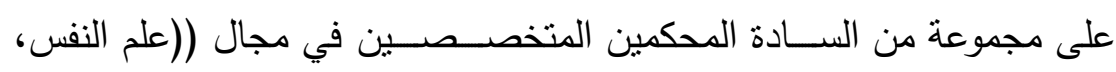

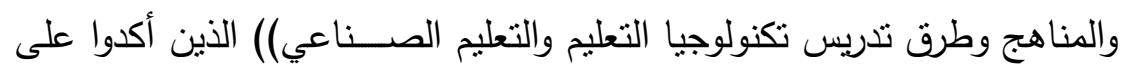
أن الاختبار يقيس ما وضع لقياسه. .rTA. البحث التربوي 


\section{المركن القومي للبحوث التبويةوالتنمية}

\section{* الصدق الثنائي (التجانس الداخلي):}

تم حســـابه من خلال العلاقات الارتباطية المتبادلة بين درجة كل شــــكل من أشـكال اختبار السـعة العقلية (البالغ عددها بـ شـكلاً) والدرجة الكلية للاختبار ككل، من خلال معامل الارتباط لبيرسون، واتضح من خلال النتائج دلالة أغلب الب التهده معاملات الارتباط عند مسـتوى ( ( +, •)، بينما كانت معاملات ارتباط الأشـكال (T، T، T) الارتباط الداخلي لمقياس السعة العقلية.

\section{• مساب ثبات الاختبار:}

قام الباحث بحساب معامل ثبات اختبار السعة العقلية ككل باستخدام معامل "ألفا كرونباخ" "Alpha-Coefficient"، وجاءت النتائج كالتالي:

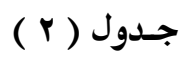

معاملات ثبات "ألفا كرونباخ" لاختبار السعة العقلية ككل

\begin{tabular}{|c|c|c|}
\hline معامل الثبات & معامل الارتباط & اختبار السعة العقلية \\
\hline$\cdot, \wedge \varepsilon$ & $O V, \leqslant 7$ & الاختبار ككل \\
\hline
\end{tabular}

يتضح من الجدول أن اختبار السعة العقلية يتميز بدرجة ثبات عالية.

"Intrinsic Validity" الصدق الذاتي (الإحصائي) "

تم حسـاب معامل الصــدق الذاتي لاختبار الســعة العقلية إحصــائيًا عن طريق الجذر التزبيعي لمعامل ثبات الاختبار ككل، وجاءت النتائج كالتالي: 


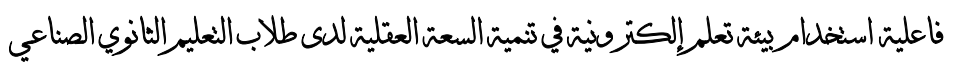

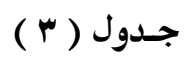

معاملات الصدق الذاتي (إحصائيًا) لاختبار السعة العقلية ككل

\begin{tabular}{|c|c|c|}
\hline الصدق الأتي & معامل الثبات & اختبار السعة العقلية \\
\hline$\cdot, 91$ & $\cdot, \wedge \varepsilon$ & الاختبار ككل \\
\hline
\end{tabular}

يتضـــح من الجدول أن اختبار الســعة العقلية يتميز بدرجة عالية من الصــدق

$$
\text { الذاتي. }
$$

\section{و - حساب متوسط زمن الاختبار :}

تم حساب متوسط زمن الاختبار عن طريق إيجاد متوسط الأزمنة التي استغرقها جميع الطلاب كل حسـب سـرعته، وتم حسـاب زمن الاختبار من خلال المعادلة الآتية:

$$
\text { الزمن الذي استغرقه كل الطلاب }
$$

وقد بلغ متوسط زمن اختبار السـعة العقلية من خلال المعادلة السـابقة ــ دقيقة

ي - الصورة النهائية لاختبار السعة العقلية:

بعد إجراء ما أوصسى به السـادة المحكمين ونتائج التجربة الاسـتطلاعية، وضـبط الاختبار إحصـائًًا أصبح الاختبار في صـورته النهائية صـالحًا للتطبيق النهائي على مجموعات البحث، ويتكون من بس شكلاً.

\section{ثانيًا: إجـراكات البمث:}

بعد الانتهاء من التجربـة الاســـطلاعيـة لأدوات البحث وإجراء التعديلات التي أسفرت عنها نتائج التجربة الاستطلاعية، وضبط الأدوات إحصائيًا أصبحت أدوات

$$
\text { . . }
$$




\section{المركن القومي للبحوث التبويةوالتنمية}

البحث جاهزة للنطبيق النهائي على مجموعات البحث من طلاب التعليم الثانوي الصــاعي بمحافظة سـوهاج، وفي ضـوء ذللك سـوف نتتاول هنا إجراءات ونتائج

$$
\begin{aligned}
& \text { البحث وتفسيرها بعد تطبيق الأدوات (قبليًا - بعديًا). } \\
& \text { الهدف من تجرية البحث: }
\end{aligned}
$$

هدفت تجربة البحث إلى تحديد فاعلية بيئة تعلم إلكترونية من خلال مقارنة نتائج

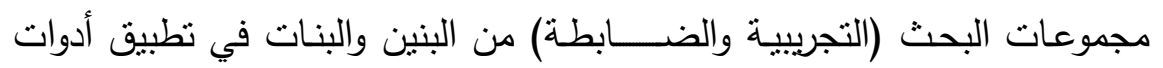
البحث التي أعدها الباحث لهذا الغرض والمتمثلة في اختبار الأثـــــال المتقاطعة "السعة العقلية" لجان بسكاليوني.

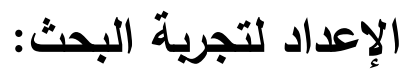

تضمن الإعداد لتجربة البحث ما يلي:

1- التسبيق الكامل مع السادة المشرفين وتحديد الجوانب الإجرائية والتتفيذية

والأخذ بارئهم وتوجيهاتهم.

r- اختيار المحافظة الذي تم فيها تطبيق البحث:

تم اختيار محافظة سوهاج للأسباب التالية: - المكان الذي تم فيه التعرف والإحساس بمشكلة البحث. - علم الباحث بتوافر التخصص والعدد المطلوب لمجموعات البحث من (البنين والبنات) بمدارس التعليم الثانوي الصناعي بمحافظة سوهاج.

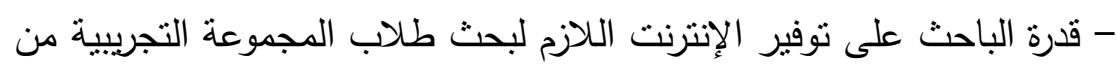
خلال بيئة التعلم الإكترونية لتطبيق تجربة البحث بمحافظة سوهاج. - حل مشكلات طلاب مدارس التعليم الثانوي الصـناعي بمحافظة سـوهاج فيما يوجهونه من مشكلات وصعوبات في دراسة مقرر "التركيبات الكهربية". 


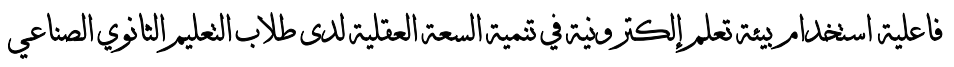

$$
\text { - تذليل العقبات الإدارية التي قد تواجه الباحث. }
$$

ب- الحصول على الخطابات والتسهيلات الإدارية اللازمة للموافقة على تنفيذ تجربة البحث.

ع- إعداد النســــخ اللازمة من أدوات البحث اختبار الســـعة العقلية لطلاب

مجموعات البحث للنطبيقين "القبلي والبعدي".

ه- التنسيق مع مديري المدارس المعنية بالتطبيق لتطبيق إجراءات البحث.

7- مستلزمات استخدام بيئة التعلم الإلكترونية:

- جهاز كمبيوتز أو تابلت: حيث ينوافر مع أغلب طلاب الصـــ الثالث

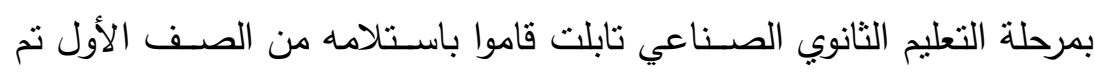

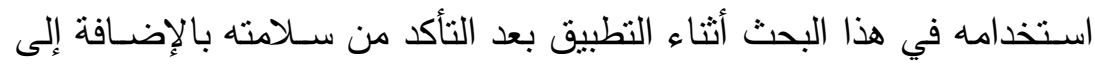

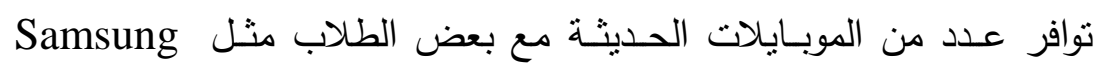
(J1 2016 - Galaxy S5 - Galaxy Core GT-18262) تنزيل متصــفـح جوجل كوروم (Google Koroom) وبرنـامج فلاش مثل على الأجهزة كي يستطيع الطلاب (Adobe Flash Player 26 PPAPI) استخدام بيئة التعلم الإكترونية. - الإنترنت: المتمثل في "الوأي فآي" الخاص بـالحكومـة الإلكترونيـة بمدارس التطبيق، وكانت معلمة الفنية الصناعية بنات بسوهاج يتوافر بمعمل الكمبيوتز

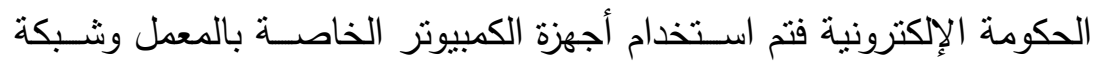

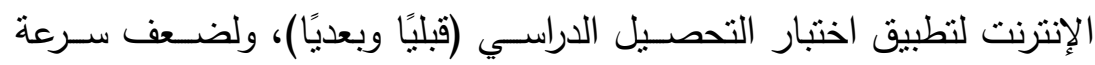
الإنترنت تم الاتفاق مع إدارات معلم مجموعات التطبيق على زيادة ســرعة 


\section{المركن القومي للبحوث التبويةوالتنمية}

الإنترنت إلى ^ جيجا بايت ودفع الفرق المادي مني للحصــــول على تحميل مناسب وجيد عند استخدام الطلاب لبيئة التعلم الإكترونية. اختيار مجموعات البحث: تم تقسيم مجموعات البحث إلى ما يلي: أ - المجموعة الاستطلاعية:

تكونت مجموعات التجربة الاســطلاعية من (0 1 ) طالب من معلمة المحاسـنة الثانوية الصناعية بنين، (10) طالبة من معلمة الفنية الصناعية بنات بسوهاج، وقد تم اختيارهم من معلمتين من مدارس التطبيق أحداهما سيكون بها المجموعة

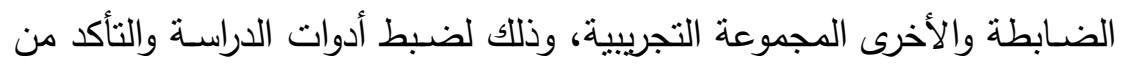
صدق وثبات اختباري السـعة العقلية المستخدمة في البحث الحالي والتحقق من

مدى قدرتهم لتحقيق الهدف المرجو . ب - المجموعات الأسساسية:

تم اختيار مجموعات البحث الأســــــية من طلاب وطالبات الصــف الثالث بالتعليم الثانوي الصــناعي تخصــص (تركيبات ومعدات كهربية) في الفصـلـ

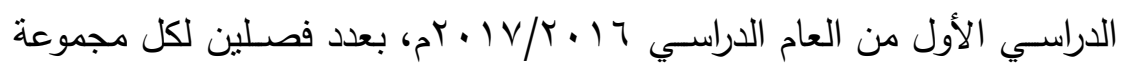
تجريبية وضابطة من كل معلمة من مدارس التطبيق (البنين والبنات)، حيث بلغ اجمالي عدد مجموعات البحث (· ؟ ؟) طالب وطالبة. التطبيق القبلي لأدوات البحث:

ولتأكد من تجانس مجموعات البحث قام الباحث بتطبيق اختبار الســــة العقلية قبليًا على المجموعة الأسـاسـية لطلاب المجموعنين التجريبيتين (بنين - بنات)، وطلاب المجموعتين الضــــابطتين (بنين - بنات)، وذلك لمدة ثمانية أيام بواقع يومين لكل مجموعة (معلمة)، وذلك بعد موافقة المركز القومي للبحوث التربويـة 


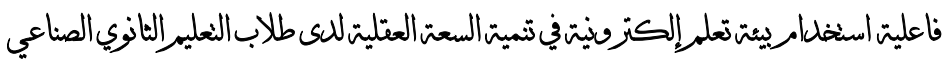

والتتميــة ومخـاطبـة آمن وزارة التربيـة والتعليم وكـان التطبيق في الفترة من

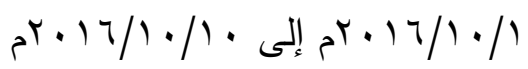

وفيما يلي عرض لنتائج التطبيق القبلي لاختبار السعة العقلية لمجموعات

$$
\text { البحث (التجريبية - الضابطة): }
$$

نجد من نتائج المقارنـة بين درجات التطبيق القبلي لاختبـار الســــة العقلية لمجموعات البحث (التجريبيتين - الضــابطتين) من البنين والبنات أن مســتوى

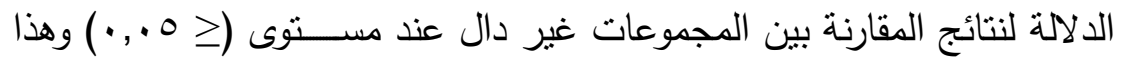
يدل على تكافؤ المجموعات فيما يتعلق باختبار الســعة العقلية، والجدول التالي يوضح ذلك:

\section{جدول ( ع )}

\begin{tabular}{|c|c|c|c|c|c|c|c|}
\hline مستوى الدلالة & قيمة (ت) & الانحراف & المتوسطات & الحستوسط & المجموعة & المجموعة & المجموعات \\
\hline \multirow{2}{*}{ غدير } & \multirow[b]{2}{*}{$\cdot, \cdot V_{r}$} & $v, r$ & \multirow[b]{2}{*}{$\cdot, 1$} & $10, \cdot r$ & 7. & ضابطة & \multirow[b]{2}{*}{ بنين } \\
\hline & & $v, r$ & & 10,1 & 7. & تجريبية & \\
\hline \multirow[b]{2}{*}{ غير } & \multirow[b]{2}{*}{$\cdot, r_{1}-$} & $v, 7)$ & \multirow[b]{2}{*}{$\cdot, r$} & $10, \cdot r$ & 7. & ضابطة & \multirow[b]{2}{*}{ بنات } \\
\hline & & $v, q 1$ & & $1 \leq, v r$ & $r$. & تجريبية & \\
\hline
\end{tabular}

الفرق بين متوسطي التطبيق القبلي لمجموعات البحث في اختبار السعة العقلية

\section{تنفيذ تجرية البحث:}

بعد اختيار مجموعات البحث (التجريبية والضــــابطة) من البنين والبنات والتأكد من تكافئها، تم تتفيذ تجربة البحث من خلال قيام الباحث بتدريس وحدتي الدراسة

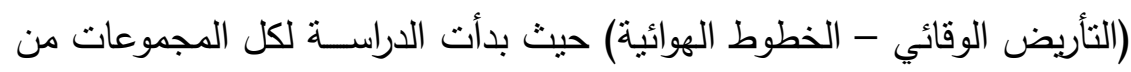
الدرس الثالث من الوحدة الأولى وهو (الالكترودات المخصصـة للتأربض)، وذللك لأن طلاب كل المجموعات كانوا قد درســـوا الدرســين "الأول والثاني" بالطربقة

$$
\text { . }
$$




\section{المركن القومي للبحوث التبويةوالتنمية}

التقليدية ولهذا تم اسـتبعاد جميع الأســـلة المتعلقة بهاتين الدرسـين من اختبار التحصيل الدراسي الإككتروني حتى لا تتأثر نتائج طلاب المجموعتين التجريبيتين بذلك، حيث نتكون الوحدة الأولى (التأريض الوقائي) من ج دروس والوحدة الثانية

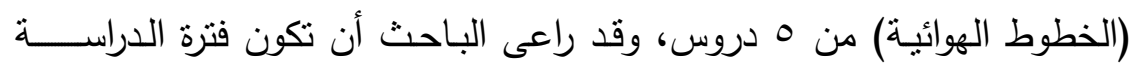
لطلاب المجموعتين (الضـــابطتين والتجريبيتين) داخل مدارس التطبيق في بداية

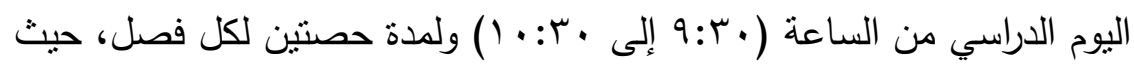

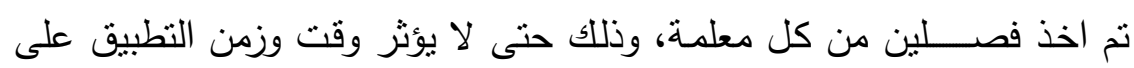
النتائج، وتم تسهيل ذلك بالتعاون مع إدارات مدارس التطبيق.

\section{خطوات تنفيذ تجربة البحث:}

أ- بالنسبة للمجموعتين التجريبيتين (بنين - بنات):

تم إعداد أدوات ومستلزمات استخدام بيئة التعلم الإلكترونية قبل استخدام الطلاب لها وتم توضـيح طبيعة البيئة وكيفية اســتخدامها مع تقديم الإرثــادات العامة

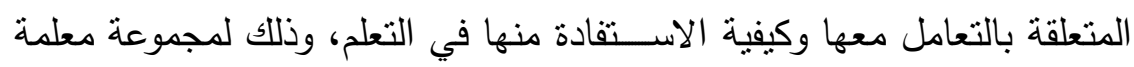
المحاسنة الثانوية الصناعية بنين، ومعلمة جرجا الثانوية الصناعية بنات بجرجا، وتم تتفيذ تجربة البحث من خلال قيام الباحث بتدربس وحدتي البحث (التأربض الوقائي - الخطوط الهوائية) من خلال بيئة التعلم الإلكترونية وتم متابعة الطلاب

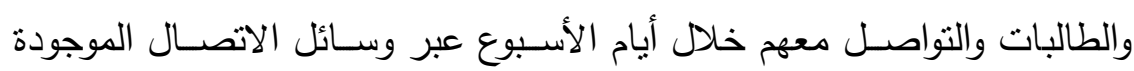
بييئة التعلم الإلكتروني للإجابة عن أي استفسار أو تزويدهم بمزيد من المعلومات لحين الالتقاء بهم في الأسبوع القادم. ب- بالنسبة للمجموعتين الضابطتين (بنين - بنات): بعد اختيار مجموعات البحث (البنين والبنات) والتأكد من تكافئها، تم تتفيذ تجربة

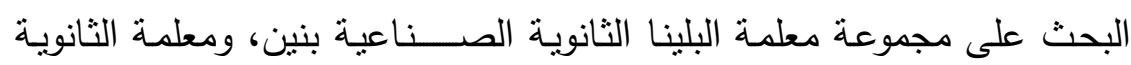


الصناعية بنات بسوهاج من خلال قيام الباحث بتدريس وحدتي البحث (التأريض الوقائي - الخطوط الهوائية) بالطريقة التقليدية وتم متابعة مجموعتي البحث من خلال الفصل الدراسي أثناء الحصة. التطبيق البعدي لأدوات البحث:

بعد الانتهاء من تتفيذ تجربة البحث تم تطبيق اختبار الســعة العقلية على طلاب كل من المجموعتين التجريبيتين والمجموعتين الضــــابطنين من (البنين والبنات) لمدة ثمانية أيام بواقع يومين لكل مجموعة (معلمة)، وذلك بعد الانتهاء من دراسـة

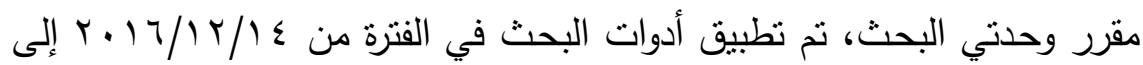
. $r \cdot 1 T / 1 T / r t$

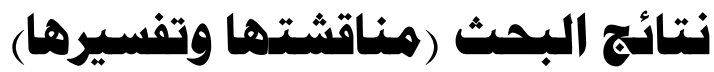

بعد تطبيق أدوات البحث تطبيقًا بعديًا نم اســتخدام البرنامج الإحصــائي (SPSS) لتحليل نتائج البحث بعد الإجابة عن سـؤال البحث والتحقق من صــحة الفروض، وتفسير النتائج، وتقديم التوصيات والمقترحات.

الإجابة عن سؤال البحث والتحقق من صحة الفروض وتفسيرها: والذي ينص على: ما فاعلية اسـتخدام بيئة التعلم الإلكترونية في تتمية السـعة العقلية

لدى طلاب التعليم الثانوي الصناعي (بنين - بنات) ذوي السعات العقلية المختلفة؟ وللإجابة على هذا السؤال تم صياغة الثلاثة فروض التالية: ا - الفرض الأول: والذي ينص على:

يوجد فرق دال إحصــائيًا عند مسـتوى دلالة (0. . • ) بين متوسـط درجات طلاب المجموعة التجريبية بنين (ذوي الســعات العقلية المختلفة) الذين درســـوا وحدتي الدراســــة (التأريض الوقائي - الخطوط الهوائيـة) من مقرر التركيبات 


\section{المركن القومي للبحوث التبويةوالتنمية}

الكهربية باســـتخدام بيئة التعلم الإلكترونية ومتوســــ درجات طلاب المجموعة الضابطة بنين (ذوي السعات العقلية المختلفة) الذين درسوا نفس المحتوى بالطريقة التقليدية المعتادة وذلك في التطبيق البعدي لاختبار الســـعة العقلية، وهذا الفرق لصسالح درجات طلاب المجموعة التجريبية، وللتحقق من صـحة الفرض الأول ثم حسـاب قيمة (ت) بين درجات طلاب المجموعة التجريبية والضــابطة من البنين وذلك في التطبيق البعدي لاختبار الســـة العقلية عن طريق برنامج (SPSS)، وكانت النتائج كما بالجدول التالي:

$$
\text { جـ (0) (0) }
$$

الفرق بين متوسطي درجات طلاب مجموعتي البحث (التجريبية والضابطة) بنين في التطبيق البعدي لاختبار السعة العقلية

\begin{tabular}{|c|c|c|c|c|c|c|c|c|}
\hline$\eta^{2}$ & مستوى اللالالة & قليمة (ت) & المعياري & الفتوسطات & الحسابي & المجموعة & المجموعة & المجموعة \\
\hline \multirow[b]{2}{*}{ \&, ६. } & $(\cdot, \cdot 1)$ & \multirow[b]{2}{*}{$\Lambda, 9 \pi$} & $11, A r$ & \multirow[b]{2}{*}{$r$} & r. & $r$ & ضابطة & \multirow[b]{2}{*}{ بنين } \\
\hline & التجريبية & & $14, \leqslant 0$ & & $00, \cdot r$ & $r$ & تجريبية & \\
\hline
\end{tabular}

تثير نتائج الجدول السابق إلى وجود فرق دال إحصائًًا عند مستوى دلالة ( +., ) بين منتوســـي درجات طلاب المجموعتين "التجريبية والضـــابطة" بنين في اختبار

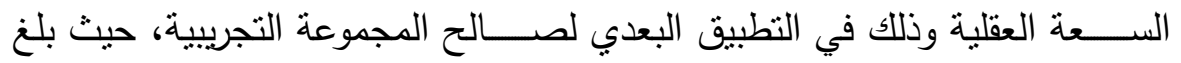
المتوســط الحســابي لدرجات طلاب المجموعة التجريبية (r •,00) وهو أكبر من المتوسط الحسـابي لدرجات طلاب المجموعة الضـابطة (• ع,ع؟)، وكان الفرق بين المتوسـطات (T7, • r)، كما أنه بالكثــ عن قيمة "ت" المحسـوبة نجد أنها بلغت

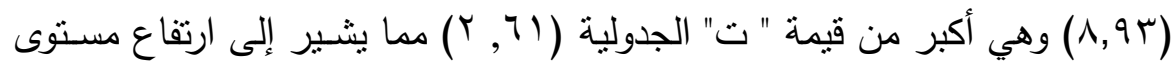


السعة العقلية لدى طلاب المجموعة التجريبية بنين في التطبيق البعدي الذين درسوا باستخدام بيئة التعلم الإلكترونية القائمة على الحوسبة السحابية عن مستوى السعة العقلية لطلاب المجموعة الضابطة بنين الذين درسوا بالطريقة التقليدية المعتادة، وقد بلغت قيمة مربع إيتا (ع , •) وهي أكبر من (r, •) مما بدل على أن اســـتـدام بيئة

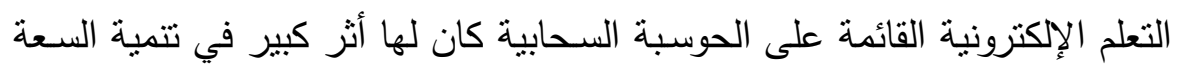
العقلية لدى طلاب المجموعة التجريبية (بنين)، ولهذا نم قبول الفرض الأول. r - الفرض الثاني: والذي ينص على:

يوجد فرق دال إحصـائيًا عند مسـتوى دلالة (0. . •) بين متوسـط درجات طلاب المجموعة التجريبية بنات (ذوي السعات العقلية المختلفة) ومتوسط درجات طلاب المجموعة الضـــابطة بنات (ذوي الســعات العقلية المختلفة) في التطبيق البعدي لاختبار الســــة العقلية، وهذا الفرق لصــــالح درجات طلاب المجموعة التجريبية، وللتحقق من صــــة الفرض الثاني تم حســاب قيمة (ت) بين درجات طلاب المجموعة التجربيية والضــــابطة من البنات وذلك في التطبيق البعدي لاختبار الســعة العقلية عن طريق برنامج (SPSS)، وكانت النتائج كما بالجدول التالي:

$$
\text { جسول ( ) ( ) ( ) }
$$

الفرق بين متوسطي درجات طلاب مجموعتي البحث (التجريبية والضابطة) بنات في التطبيق البعدي لاختبار السعة العقلية

\begin{tabular}{|c|c|c|c|c|c|c|c|c|}
\hline$\eta^{2}$ & مستوى الدلالة & قالمحسوية (ت) & الانحراف & المتوسطات & الحسابي & المجموعة & المجموعة & المجموعة \\
\hline \multirow[b]{2}{*}{$\cdot, \varepsilon$} & $(\cdot, \cdot 1)$ & \multirow[b]{2}{*}{$\Lambda, r_{0}$} & $|1, r|$ & \multirow[b]{2}{*}{19,1} & $r r, q$. & 7. & ضابطة & \multirow[b]{2}{*}{ بنات } \\
\hline & التجراح & & $1 \leq,+1$ & & or,... & 7. & تجريبية & \\
\hline
\end{tabular}

$$
\text { . - }
$$




\section{المركن القومي للبحوث التبويةوالتنمية}

تثير نتائج الجدول السابق إلى وجود فرق دال إحصائيًا عند مستوى دلالة ( •., ) بين منوسـطي درجات طلاب المجموعتين "التجريبية والضــابطة" بنات في اختبار

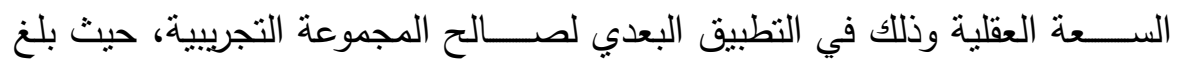

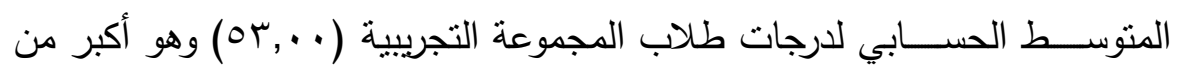

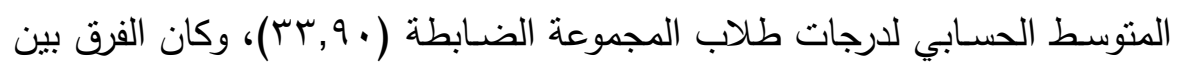

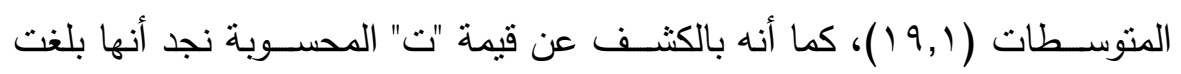

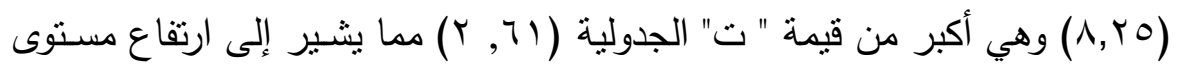

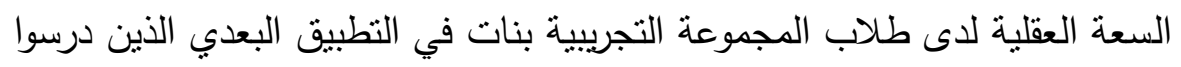

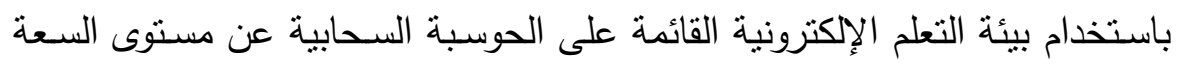

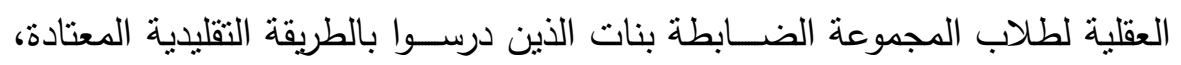

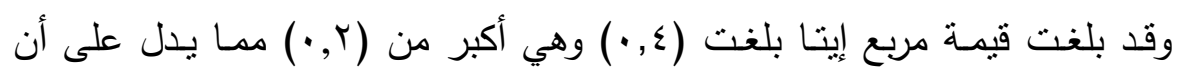

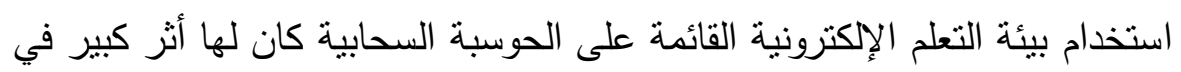

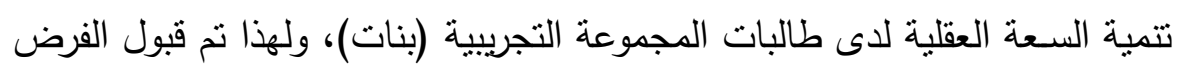
الثاني. r- الفرض الثالث: والذي ينص على:

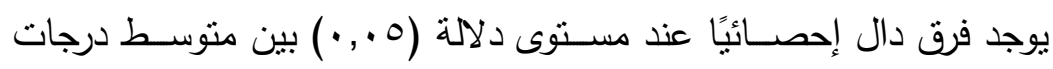

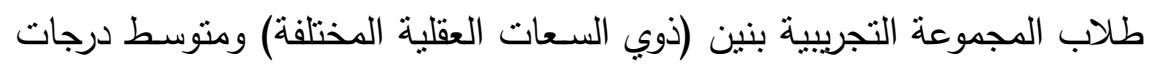

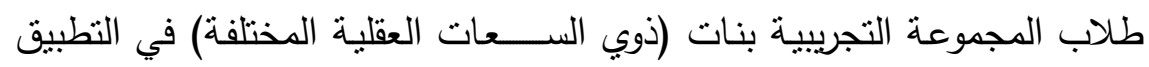

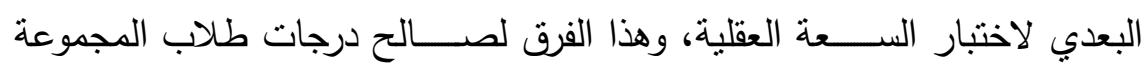

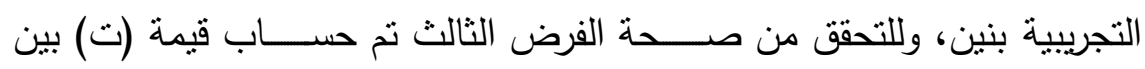

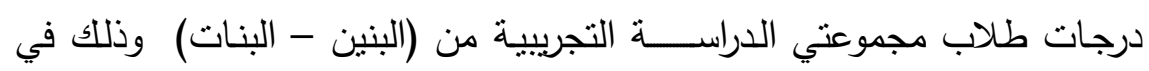




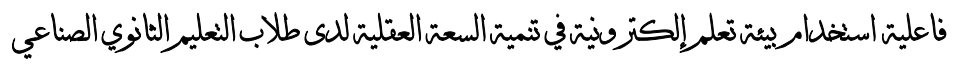

التطبيق البعدي لاختبار الســــة العقلية عن طريق برنـامج (SPSS)، وكانت

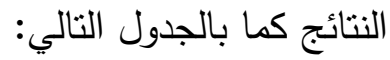

$$
\text { ( ) جسدول ( ) }
$$

الفرق بين متوسطي درجات طلاب مجموعتي البحث التجريبية (البنين والبنات) في التطبيق

البعدي لاختبار السعة العقلية

\begin{tabular}{|c|c|c|c|c|c|c|c|c|}
\hline$\eta^{2}$ & لدلالة & قالمحسوية (ت) & الانحراف & المتوسطات & الحسابي & المجموعة & المجموعة & المجموعة \\
\hline \multirow[b]{2}{*}{$\cdot, . \bullet$} & \multirow{2}{*}{ لصالح البنين } & \multirow[b]{2}{*}{ Y, } & $I T, I V$ & \multirow[b]{2}{*}{ ه } & $\diamond \wedge, r \wedge$ & 7. & تجريبية & بنين \\
\hline & & & or, & & $O r, \cdot r$ & 1. & تجريبية & بنات \\
\hline
\end{tabular}

يتضـح من نتائج الجدول السـابق وجود فرق دال إحصـائيًا عند مستوى دلالة ( ( +, • ) بين منوســطي درجات طلاب مجموعتي الدارســـة التجريبية "بنين - بنات" في النطبيق البعدي لاختبار السـعة العقلية لصـالح البنين، حيث بلغ المتوسـ الحسـابي

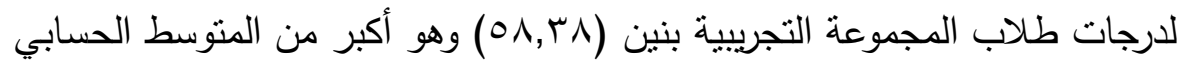
لـدرجـات طلاب المجموعـة التجريبيـة بنـات (r., بror)، حيـث كـان الفرق بين

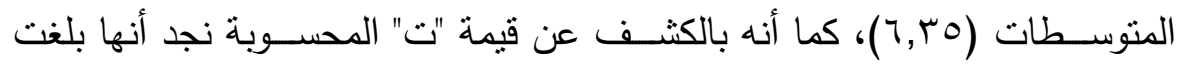

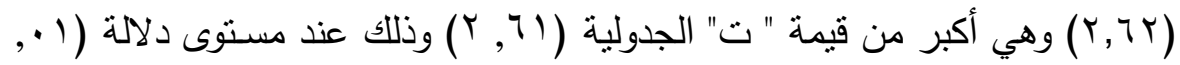
• )، الا أن الفرق بين المتوسـطات لا يدل على وجود تأثثر حيث أنه بحسـاب قيمة مربع إيتا اتضـح أنها بلغت (0. . •) وهي أقل من (r, ·) مما بثـير إلى عدم وجود اختلاف كبير في مســتوى الســـعة العقلية لدى طلاب المجموعة التجريبية بنين وطـالبـات المجموعـة التجريبيـة بنـات وذلك في التطبيق البعدي، ولهذا نم رفض الفرض الثالث. 


\section{المركن القومي للبحوث التبويةوالتنمية}

تعليق على نتائج فروض البحث:

يرجع الباحث نتائج الفرضين (الأول والثاني) إلى ما يلي:

زيادة كفاءة الســـة العقلية في تشـــيل ومعالجة المعلومات عن طريق تتســيق

وتتظيم المعلومات في صـــورة خطوات متتابعة عبر بيئة التعلم الإلكتروني، حتى

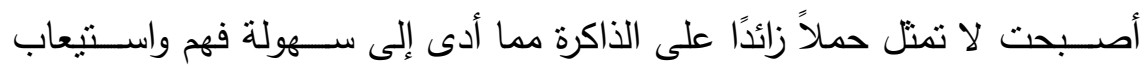

وتذكر المفاهيم والمعلومات داخل الذاكرة.

تقدم المعلومات عبر بيئة التعلم الإلكترونية القائمة على الحوســبة الســحابية من خلال مثيرات مختلفة واشتراك الحواس المتعددة (السمعية - البصرية - ... ) في اســتقبالها وإدراكها جعها أكثر تأثيرًا وفاعلية في كل من الذاكرة طويلة المدى ولى وقصـيرة المدى، مما ســـل على الذاكرة طويلة المدى الاحتفاظ بالمعلومات لفترة طويلة. تدعيم الدروس بالصـــور والرســـوم والأثــــال التوضـــــية والأوان والحركات والأصـــوات بسـر على الطلاب معالجة المعلومات بالذاكرة والوصــل بين ذاكرة الطالب والمادة المتفاعل معها عبر بيئة التعلم الإلكتروني القائمة على الحوســـبة السحابية وجعلة يركز اهتمامه على التفصيلات الدقيقة للمادة التعليمية مما يعتبر بمثـابـة ترميز مزدوج للمـادة في ذاكرة الطـالب يؤثز هـذا الترميز على تـكر واستذعاء الطالب للمعلومات. احتواء بيئة التعلم الإلكترونية القائمة على الحوســـبة الســـحابية على فيديوهات

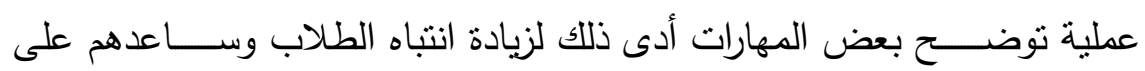
الاحتفاظ بالمعلومات لفترة طويلة.

• إكانية إطلاع وتعلم كل طالب المحتوى التعليمي عبر بيئة التعلم الإلكتروني في أي وقت وأي مكان متصــل بالإنترنت أداء إلى تقوية الوصــلات العصــبية التي 


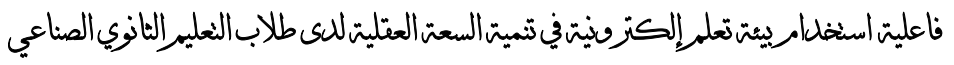

تثبت أثنار التعلم وتسـاعد على ترتيب المعلومات والفهم والاستيعاب والتذكر داخل

الذاكرة.

تكامل المعلومات اللفظية والمرئية التي تتيحها بيئة التعلم الإلكتروني ســــاعد في استدعاء العناصر التي تتمي السعة العقلية.

الخطوات العلمية المنظمة التي اتبعها الباحث في تصــميم بيئة التعلم الإكترونية والتي اعتمدت على نموذج التصميم التعليمي المقترح من الباحث. اختبار أسـلوبين في عرض المحتوى (الخطي - التشـعبي) ســـل وبســـ عملية التعلم. استخدام أكثر من طريقة في تتاول الدرس عبر بيئة التعلم الإلكترونية القائمة على الحوسبة السحابية كالعرض والنقاش وتتوع وسائل التواصل مع الطلاب. - توفير بيئة تعلم إلكترونية نفسية واجتماعية مناسبة لمواقف التعلم المختلفة. تتميز المرحلة العمرية ما بين (V I - 9 ( ) سـنة لطلاب هذه الدراسـة بخصسائص مهمة تخدم البحث الحالي والمتمثلة في: - أولا: من الناحية العقلية: - تطور النمو العقلي تطورًا كبيرًا كمًا وكيفًا. - نمو الذكاء العام وزيادة التباين في القدرات العقلية والميول. - زيادة الاعتماد على الفهم والاستدلال بدل من الحفظ المجرد. - ثانياً: من الناحية الاجنماعية: - - الرغبة في توجيه الذات. - مات.

- الاستقلالية والاتجاه أكثر نحو الاعتماد على النفس والتعلم الذاتي. - تحمـل المســئوليـة واختيـار العمـل المرغوب في مزاولتهه والتخطيط والاستعداد له. 


\section{المركن القومي للبحوث التبويةوالتنمية}

$$
\text { - اكتساب مفاهيم واتجاهات مرغوبة. }
$$

وتتفق هذه النتائج مع نتائج البحوث والدراسـات التي أكدت أهمية اسـتخدام

التكنولوجيا في تتمية السعة العقلية في مراحل التعليم المختلفة مثل دراسـة كلً من:

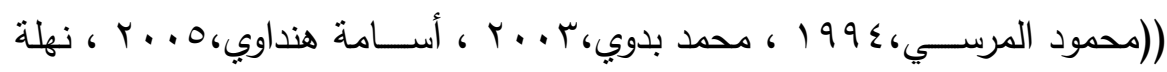

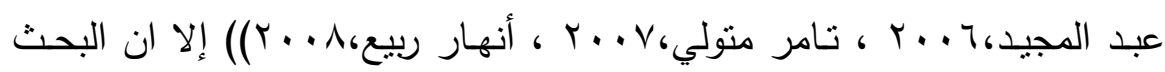
الحالي اعتمد على بيئة التعلم الإلكتروني في تتمية الســـعة العقلية بمرحلة التعليم الثانوي الصناعي.

ويهذا نكون قد توصلتا إلى الإجابة عن سـؤال البحث والأي ينص على: مـا فاعلية بيئة التعلم الإلكترونية في تتمية الســــة العقلية لدى طلاب التعليم الثانوي الصناعي (بنين - بنات) ذوي السعات العقلية المختلفة؟

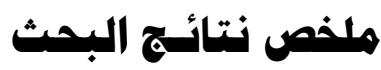

توصل البحث الحالي إلى النتائج الآتية:

- ارتفاع مسـتوى السـعة العقلية لدى طلاب المجموعة التجريبية بنين الذين درسـوا

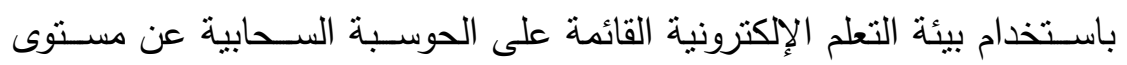
السـعة العقلية لطلاب المجموعة الضـابطة بنين الذين درسـوا بالطريقة التقليدية

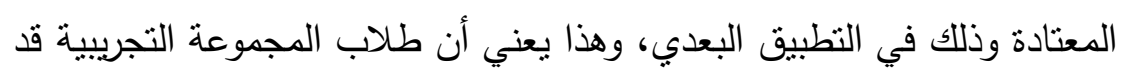

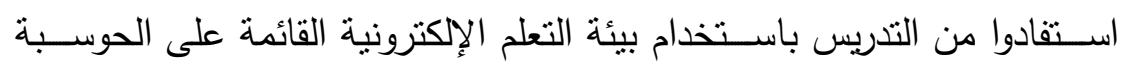

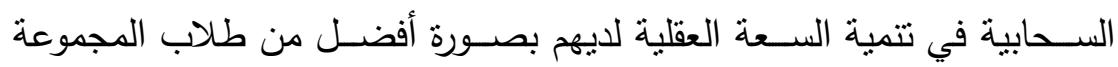
الضابطة.

- ارتفاع مستوى السعة العقلية لدى طالبات المجموعة التجربيية بنات الذين درسوا

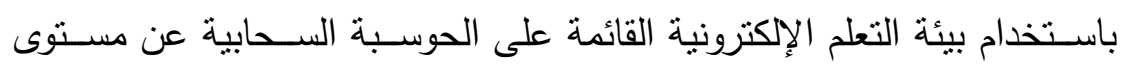




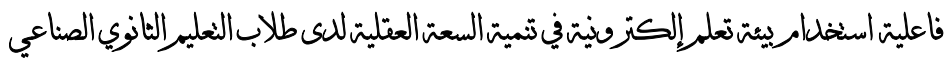

السـعة العقلية لطالبات المجموعة الضـابطة بنات الذين درسـوا بالطريقة التقليدية

$$
\text { المعتادة وذلك في التطبيق البعدي. }
$$

- عدم وجود فرق في مسـتوى السـعة العقلية بين طلاب المجموعة التجريبية بنين وطالبات المجموعة التجريبية بنات وذللك في التطبيق البعدي.

\section{وفي ضوء ما توصل إلية الباحث من نتائج، فإنه يوصي بما يلي:}

ا- الاسـتفادة من المعايير التصـميمية التي تم وضـعها في بيئة التعلم الإككترونية

$$
\text { في برامج إعداد معلم التعليم الصناعي. }
$$

ץ- تصـميم بيئات تعلم إلكترونية يمكن من خلالها تتمية مهارات التصـميم التعليم

$$
\text { لاى معلمي التعليم الصناعي. }
$$

ب- ضـرورة تفعيل التدريس والاسـتفادة من بيئات التعلم الإكترونية لدراسـة طلاب التعليم الثانوي الصـناعي المقررات النظرية من خلالها في أي وقت وأي مكان يتتاسب معهم بما يتواكب مع التطورات التكنولوجية الحديثة. ع- ضـرورة توفير دورات تدربيية لمعلمي التعليم الثانوي الصـناعي لنتمية مهاراتهم في تصــميم المقررات الإككترونية ونشـرها عبر الإنترنت لتكون متاحة في أي

$$
\text { وقت ومن أي مكان. }
$$

0- - ضـــرورة الاهتمام بطرق تدريس منتوعة تتماثـــي مع طبيعة مقررات التعليم

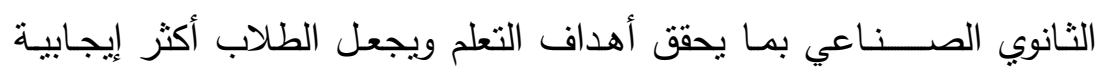
وتفاعل. 


\section{المركن القومي للبحوثالتهبيةوالنمية}

\section{بحسوث همترجهـه:}

في ضوء نتائج هذا البحث يقترح الباحث مجموعة من الأبحاث المستقبلية التالية:

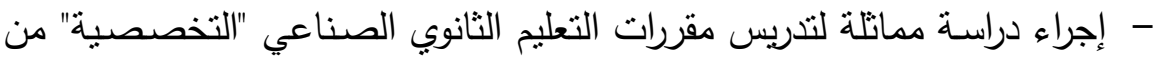
خلال بيئات تعلم إلكترونية أخرى مثل (التفاعلية، التكيفية، التشاركية، التعاونية، ـ ... غيرها) تتتاسب مع كل مستوى من مسنويات السعة العقلية المختلفة.

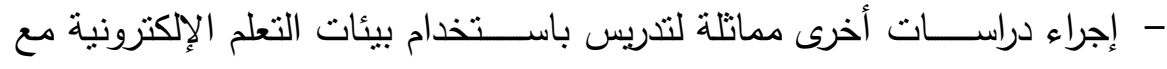
متغيرات تابعة أخرى مثل (تتمية مهارات التعامل مع التكنولوجيا، الاتصـــال الوظيفي، التواصـل الاجتماعي، الاتجاه نحو المهنة، سـوق العمل، ... وغيرها) لاى طلاب التعليم الثانوي الصناعي.

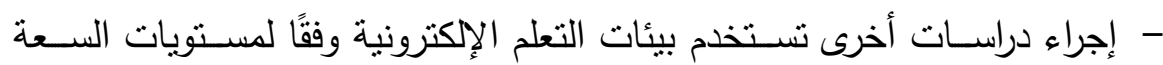
العقلية وأسلوب التعلم لدى طلاب التعليم الثانوي الصناعي. 


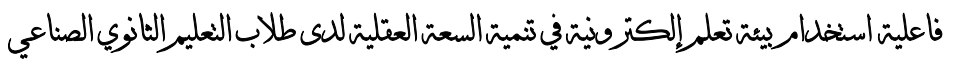

\section{المراجــع}

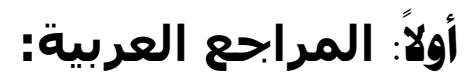

- أحمد سالم.(ع . . ؟). تكنولوجيا التعليم والتعلم الاكتروني. الطبعة الأولي: الرباض. مكتبه الرشد ناشرون.

- إيهاب جودة، احمد طلبة.(1991). فاعلية استخدام استراتيجية مقترحة في تتمية

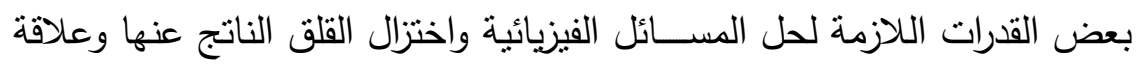
ذلك بالسـعة العقلية لدى طلاب المرحلة الثنانوية. رســالة دكتوراه. كلية التربية. جامعة طنطا.

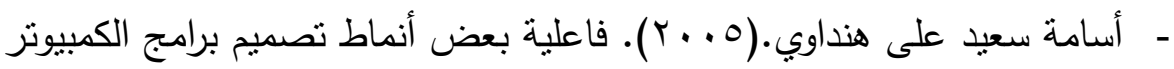

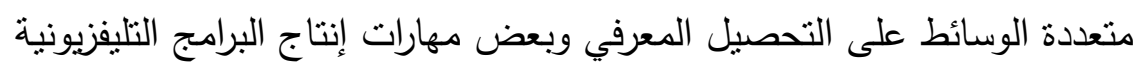
التعليمية لطلاب شعبة تكنولوجيا التعليم تفكيرهم الابتكاري في التطبيقات التعليمية للإنترنت. رسالة دكتوراه. كلية التربية. جامعة الأزهر .

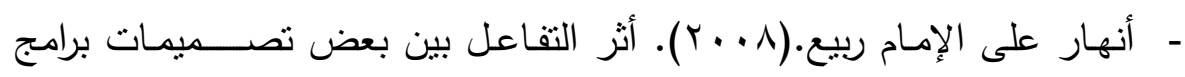

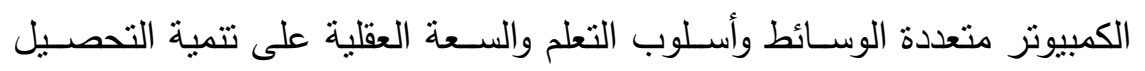

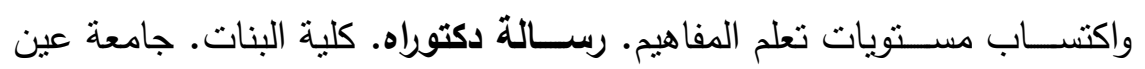
شمس. - إسعاد عبد العظيم البنا، وحمدي عبد العظيم البنا.(.991). اختبار الأثكال المتقاطعة. كراسة التعلبيات. المنصورة: دار عامر .

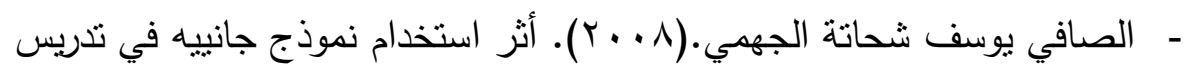

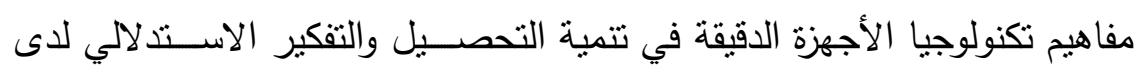

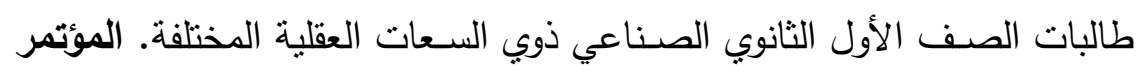




\section{المركن القومي للبحوث التبويةوالتنمية}

العلمي العشــرون: مناهج التعليم والهوية الثقافية. الجمعية المصــرية للمناهج وطرق التدربس.

- تامر منولي.(V . . . Y). أثز الواقع الافتراضي وعروض الفيديو كأحد أدوات التعليم الإكتروني على السـعة العقلية لاى طلاب تكنولوجيا التعليم. رسـالة ماجسـتير. كلية التربية النوعية. جامعة طنطا.

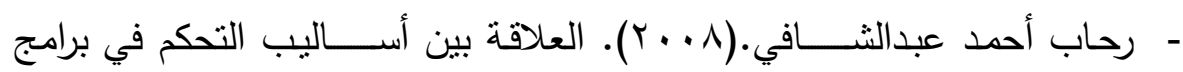
الكمبيوتز التعليمية ومستويات السعة العقلية للمتعلمين وبين كفاءة التعلم. رسـالة ماجستير • كلية التربية. جامعة حلوان. - سماح محمود إبراهيم محمود.(9 . . r). نمو المفاهيم الرياضية لدى تلاميذ الحلقة

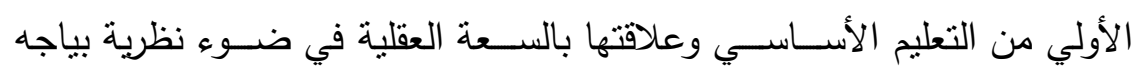
الجديدة. رسالة دكتوراه. كلية التربية. جامعة حلوان.

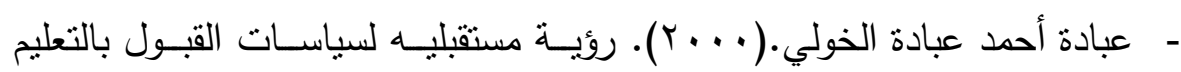
الصــــاعي ومناهجه. ورقة عمل مقدمة للمؤتمر العلمي الثاني: "لدور المتغير للمعلم العـربي في مجتمع الغـد". كلية التربية. جامعة أسيوط ^1 1 - . ب أبريل .

$$
\text { ص ص ص VA }
$$

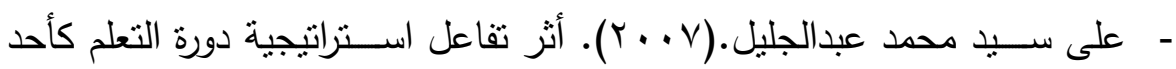
اســراتيجيات التعلم النشـــ والسـعة العقلية في تتمية بعض المفاهيم الميكانيكية وبقاء أثز التعلم لدى تلاميذ المدارس الثانوية الصــــناعية. مجلة كلية التربية. جامعة أسيوط.

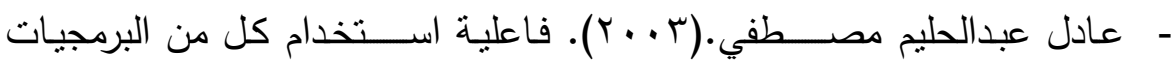

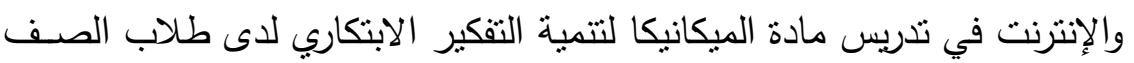




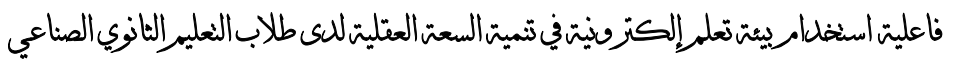

الثالث الثانوي ذوي الســـعات العقلية المختلفة. رســــالة دكتوراه. القاهرة: كلية

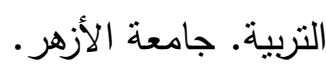

- عبدالعزيز عبدالحميد طلبه.( • • ( ). التعليم الإكتروني ومسـتحثثات تكنولوجيا التعليم. المنصورة: المكتبة العصرية للنشر والتوزيع. - عبدالوهاب محمد كامل.(99 (1)). علم النفس الفســيولوجي. الطبعة الثانية. القاهرة: مكتبة النهضة المصربة. - محد السـيد على، ومحرز عبده يوسـف الغنام.(999 (199). فعالية اسـتخدام بعض اســتراتيجيات تجهيز المعلومات في التحصـــيل والقدرة على حل المشــــلات الكيميائية لدى طلاب الصف الأول الثانوي ذوي السـعات العقلية المختلفة. مجلة التربية العلمية. الجمعية المصـــرية للتربية العلمية. العدد الرابع. المجلد التاني

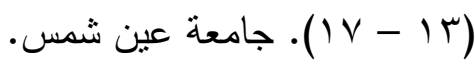

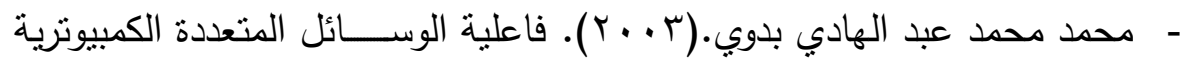
ومسـتويات مختلفة للسـعة العقلية في تتمية مهارات التعلم الذاتي والتحصسيل لدى تلاميذ المرحلة الإعدادية في مادة العلوم. رســالة دكتوراه. القاهرة: كلية التربية.

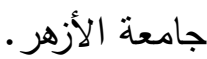

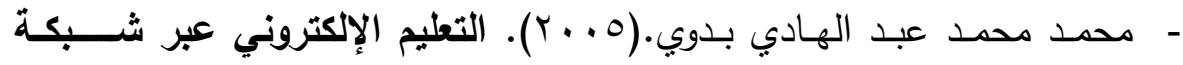
الإنترنت. القاهرة: الدار المصرية اللبنانية.

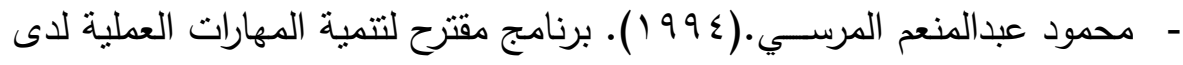
طلاب النسيج بالمعلمة الثانوية الصناعية وعلاقة مستوى الأداء بكل من السعة العقلية والأساليب المعرفية. رسالة ماجستير. كلية التربية. جامعة المنصورة. - مطهر أحمد مطهر حميد.(10 • (1). بيئة إلكترونيـة مقترحة قائمسة على التعلم التعاوني وأثرها في تتمية كفايات توظيف أدوات الجيل الثاني للويب في التعليم 


\section{المركن القومي للبحوثالتبوبةوالتنمية}

لدى طلاب كلية التربية والعلوم التطبيقية بجامعة حجة واتجاهاتهم نحوها. رسـالة دكتوراه. كلية الدراسات العليا للتربية. جامعة القاهرة.

- هناء عبده على عباس.(1991 (99). التفاعل بين بعض أســاليب التدريس والســعة

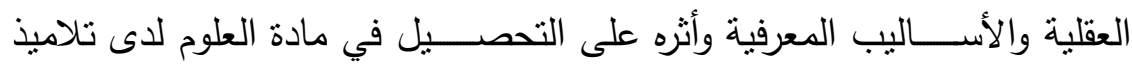
الصـف الثاني الإعدادي. رسـالة ماجسـتير غير منشـورة. كلية التربية. جامعة

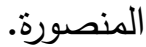

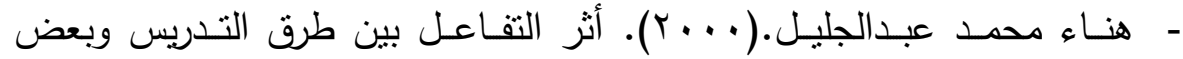
الاســتعدادات على تتمية المفاهيم العلمية في مادة العلوم لدى تلاميذ المرحلة الإعدادية. رسالة ماجستير . كلية التربية. جامعة الزقازيق.

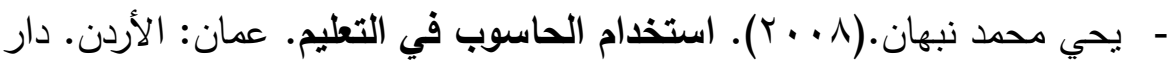
اليازوري العلمية للنشر والتوزيع. ثانيًا: المرابع الأبحنبية:

- Dron, J., Bhattacharya, M. (2007). A Dialogue on ELearning and Diversity: the Learning Management System vs the Personal Learning Environment. In G. Richards (Ed.), Proceedings of World Conference on ELearning in Corporate, Government, Healthcare, and Higher Education.

- Johnstone, A. H. \& El-Banna, H. (1998). Capacities demands and processes a predictive model for science education. Education in Chemistry. 23, (2), 80-84

- Lawson, A. E. (1983). Predicting science achievement the role of developmental level, Disembodying ability, mental capacity, prior knowledge and beliefs, journal of research in science teaching. 20(@), 117-129. 


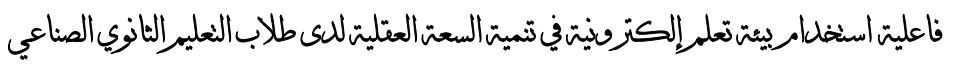

- Kenneth, D. R. (1980). Relation among M-power, teaching methodology, cognitive development. And content achievement Diss. Abs. 41(6), 2541.

- Niaz, M. and Robinson, W. (1991). Teaching algorithmic problem solving or conceptual understanding : Role of developmental level, mental capacity, and cognitive style. (ERIC Document Reproduction Service No .ED 331717). 